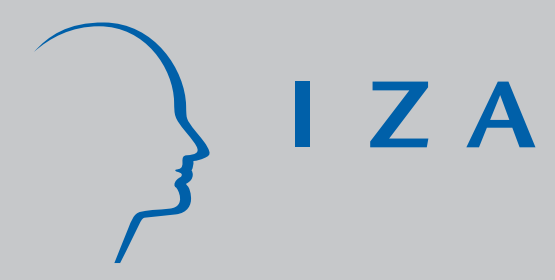

IZA DP No. 1572

Two-Sided Search, Heterogeneous Skills and Labor Market Performance

Samuel Danthine

April 2005 


\title{
Two-Sided Search, Heterogeneous Skills and Labor Market Performance
}

\author{
Samuel Danthine \\ Université du Québec à Montréal, CIRPÉE \\ and IZA Bonn
}

Discussion Paper No. 1572

April 2005

IZA

P.O. Box 7240

53072 Bonn

Germany

Phone: +49-228-3894-0

Fax: +49-228-3894-180

Email: iza@iza.org

\begin{abstract}
Any opinions expressed here are those of the author(s) and not those of the institute. Research disseminated by IZA may include views on policy, but the institute itself takes no institutional policy positions.

The Institute for the Study of Labor (IZA) in Bonn is a local and virtual international research center and a place of communication between science, politics and business. IZA is an independent nonprofit company supported by Deutsche Post World Net. The center is associated with the University of Bonn and offers a stimulating research environment through its research networks, research support, and visitors and doctoral programs. IZA engages in (i) original and internationally competitive research in all fields of labor economics, (ii) development of policy concepts, and (iii) dissemination of research results and concepts to the interested public.
\end{abstract}

IZA Discussion Papers often represent preliminary work and are circulated to encourage discussion. Citation of such a paper should account for its provisional character. A revised version may be available directly from the author. 


\section{ABSTRACT \\ Two-Sided Search, Heterogeneous Skills and Labor Market Performance*}

A quantitative model of two-sided search with ex-ante heterogeneity in both worker and entrepreneurial skills is proposed. It is possible to characterize both the competitive equilibrium and the optimal solution numerically. The competitive equilibrium is shown to be suboptimal. Less-skilled workers and firms are too selective, not matching with their comparable counterparts. High-types, on the other hand, are not selective enough. The model shows promise as a tool for evaluating the effects of labor policies (and other changes in the economy) on the composition of unemployment and on unemployment duration, as well as on wage distributions. The effect of introducing a simple unemployment insurance scheme is then twofold. First, it increases unemployment by allowing a greater proportion of low types not to match, which decreases output. Second, it decreases mismatch, which has a positive effect on output. It is possible to have a positive effect of unemployment insurance on productivity and find the optimal level of unemployment insurance. Finally, it is shown that assuming risk-neutral workers in this model is not innocuous.

JEL Classification: J63, J65, J31

Keywords: two-sided search, heterogeneity, unemployment, unemployment insurance, risk aversion

Corresponding author:

Samuel Danthine

Department of Economics

Université du Québec à Montréal

PO 8888, Downtown Station

Montréal (QC) H3C 3P8

Canada

Email: danthine.samuel@uqam.ca

\footnotetext{
* This paper is a revised version of the second chapter of my thesis, and owes much to my advisor, Jeremy Greenwood. Hugo Hopenhayn and Jean-Pierre Danthine have contributed their fair share of time and comments! Thanks are due to Tom Cooley who provided financial support from NSF grant SES-0111518. Discussions with Stephane Auray, Mark Bils, Jeff Campbell, Betsy Caucutt, Fatih Guvenen, Per Krusell, Lance Lochner, Toshi Mukoyama, Joseph Perktold, Richard Rogerson, Robert Shimer, Tony Smith, Alan Stockman and Randy Wright were important. Comments by participants at Rochester, UQAM, SED 2003 and EEA-ESSEM 2003 contributed to the final outcome. Many mistakes have been eliminated, thanks to all of the above; the remaining are undoubtedly mine.
} 


\section{Introduction}

People face different labor market experiences and vary in labor status (in/out of the labor force, employed/unemployed). Individuals differ in the duration of unemployment spells as well as in the number of these spells. Different people earn different wages and work different numbers of hours. These differences across individuals are partly due to observable idiosyncratic characteristics. They are also partly attributable to unobservable individual characteristics, and to firm characteristics. At country level, there is a wide variance in labor market performance. Country differ in labor force participation, in unemployment rates, in unemployment duration but also in the distribution of unemployment across individuals, and in wage dispersion. In addition, countries differ in labor market productivity.

This paper introduces a (quantitative) two-sided search model with ex-ante heterogeneity that generates within-skill wage heterogeneity and skill-related unemployment duration to account for these facts. What results is a rich description of equilibrium where labor policies have implications that go far beyond their effects on the level of current unemployment and aggregate output. In this model, policies, institutions and individual characteristics may result in more or less unemployment as well as in better or worse sorting of skills. As a result, the size of the pie - the level of aggregate output - but also the way it is distributed - the degree of wage and income inequality - are affected in non trivial and interesting ways.

The essentials of the model are as follows. Time elapses discretely. The economy is inhabited by risk averse workers, risk neutral firms, and a government. Workers differ in skills, and firms (entrepreneurs) differ in productivity (skills). Search is not directed, in the sense that workers or firms do not know where to find a specified match with a given payoff and probabilities of acceptance. Meetings take place randomly. A matched pair bargains over wages and decides whether to engage in production or not. Skills evolve over time, so a productive pair revises the contract at the beginning of each period, and may decide to split. The assumptions on skill behavior and bargaining are similar to those in Aiyagari, Greenwood, and Guner (2000) and Greenwood, Guner, and 
Knowles (2003), but with infinitely-lived agents. Equilibrium displays wage inequality as well as within-skill wage inequality.

A planner's problem is set up and an original method to solve numerically for the stationary optimum is advanced. Solving the planner's problem is not straightforward. The optimal decision rule depends on current and future distributions, and these distributions, in turn, depend on the decision rule. The method deals with this feature by forcing the planner to choose a decision rule for all future periods, finding the associated stationary distribution and iterating. The solution to such a problem is a stationary optimum only if the initial distribution is the stationary distribution associated with the solution. Using the distribution found at the end of the previous iteration as an initial distribution for the next, and repeating quickly leads to the stationary optimum. The proposed method should be useful to solve for the planner's problem in models with heterogeneous agents in which the planner's choice variables are distributions.

It is interesting to compare the equilibrium and the optimal solution. As is often the case in search and matching environments, the equilibrium is sub-optimal. In equilibrium, low types are too selective, refusing to match with their counterparts, and high types are not selective enough. This is due to externalities that are not internalized: indeed, when a low-type worker is searching, he decreases the quality of the pool of searchers. When he meets a low quality firm, it is best for the economy that the two match, increasing the quality of the pool of searchers. This does not always happen in equilibrium, however. On the other hand, when a high-productivity firm and a low-skilled worker meet, it is optimal that they refuse to match if there are enough high-types searching. But the high-skilled entrepreneur does not take into account the externality he imposes on high-skilled workers by accepting to match with the lowskilled worker. The same argument holds for a high-skilled worker accepting to work for a low-skilled firm. Contrasting the equilibrium and the planner's solution underlines the importance of unemployment composition. Two economies might have the same level of unemployment, with one being optimal while the other is not. Introducing a simple unemployment insurance scheme encourages all types to be pickier. This 
has two effects. One is to increase the level of unemployment, which has negative impact on output. Low types are now even less likely to match together, a move away from the optimal solution. The second effect is to make high types more picky, thus decreasing the degree of mismatch and bringing the economy closer to the optimal solution. When this second effect dominates, unemployment insurance has a positive effect on output, which helps explain differences between the labor market performance of various countries.

While most models of search and matching are concerned with risk-neutral worlds, workers in the model presented here are assumed to be risk-averse. It seems paradoxical that a micro-oriented approach like search and matching assumes risk-neutrality, while representative-agent frameworks center around risk-averse agents. The importance of assuming risk-neutrality in this model context is examined. It turns out that the degree of workers' risk aversion is an important determinant of the distance between equilibrium and optimal performance, and that it affects the distribution of unemployment, unemployment duration, and wages. This result follows because risk aversion affects the value of outside options and, as a result, the quality of sorting at equilibrium. As a corollary, the impact of unemployment insurance is also shown to differ under alternative assumptions about risk aversion.

These results have some similarities with a number of papers that contrast optimum and equilibrium. Shimer and Smith (2001) present a model with risk-neutral agents on both side of the market, immutable types and entry and exit, characteristics that differentiate their model from the one in this paper. They show that a type-specific search tax can decentralize the optimal solution. Shi (2001) contrasts optimum and equilibrium in a static model with heterogeneous agents and wage posting. In his model, the distribution of machines is endogenous. He shows that, when the complementarity between machines and worker skills is low, the optimum may be non-assortative. Davis (2001) has a static model with endogenous distribution of machines and a constantreturns-to-scale matching function. His approach is similar to that of Hosios (1990), but with agent heterogeneity. He shows that there is a fundamental tension between 
the condition for an efficient mix of jobs and the condition for an efficient total supply of jobs.

The game plan from this point on is as follows. First, the model is set up and an equilibrium is defined. Next, some numerical results pertaining to the equilibrium are presented, and a discussion of the optimality of the equilibrium is put forward. The planner's problem and a problem analogous to the Golden Rule are then set up and solved. The impact of introducing a simple unemployment insurance scheme is analyzed, and robustness to changes in parameters is discussed, with special emphasis on risk aversion and match complementarity. This leads to the conclusion.

\section{The Model}

The economy is inhabited by infinitely-lived workers and entrepreneurs, as well as a government. ${ }^{1}$ Time is discrete. There is no entry and no exit in the market. Both the population of workers and the population of entrepreneurs are heterogeneous: they vary in productivity levels. A worker's productivity level is labelled by $z \in Z=\left\{z_{1}, \ldots, z_{N}\right\}$, while a firm's productivity is denoted by $x \in X=\left\{x_{1}, \ldots, x_{M}\right\}$. A worker of type $z_{l}$ evolves to type $z_{k}$ with transition probability $Z(k \mid l)$. Similarly, a firm's productivity evolves from $x_{i}$ to $x_{j}$ following the transition probability $X(j \mid i)$. In each period, in the matching market, a given firm meets a worker of type $z_{k}$ with probability $\Omega_{k}$. It must be the case that $\sum_{k} \Omega_{k} \leq 1$. The odds that a worker meets a firm of type $x_{i}$ is given by $\Phi_{i}$, where $\sum_{i} \Phi_{i} \leq 1$. The last two inequalities hold with equality when the number of firms and workers searching are the same and there is no congestion. An important step in solving the model is to find these stationary probabilities.

The timing of the model is as follows. At the beginning of a given period, there are matched and vacant firms, and employed and unemployed workers. All agents learn their new type, and make their decisions knowingly. Unemployed workers and vacant firms are drawn into pairs. All pairs of workers and firms, whether newly matched

\footnotetext{
${ }^{1}$ Again, the words 'firms' and 'entrepreneurs' are used interchangeably here.
} 
or previously matched, bargain over wages taking current types as given, and decide whether or not to contract. If the contract suits both agents, they engage in production and share the surplus accordingly. If either refuses the bargained wage, the firm does not produce for a period, while the worker collects unemployment benefits, if any, and may engage in home production. All workers produce the same amount $h$ at home. They may be subject to an income tax at the rate $\tau$. Let entrepreneurs evade taxes. The government collects taxes and pays unemployment benefits $b$ under a balanced budget requirement. The case where government does not pay unemployment benefits is obtained by setting $b$ and $\tau$ to 0 . The values of being matched or not are now defined, and the bargaining problem is set up. All consumption takes place at the end of the period. Figure 1 summarizes the timing of the economy.

Figure 1: Timeline

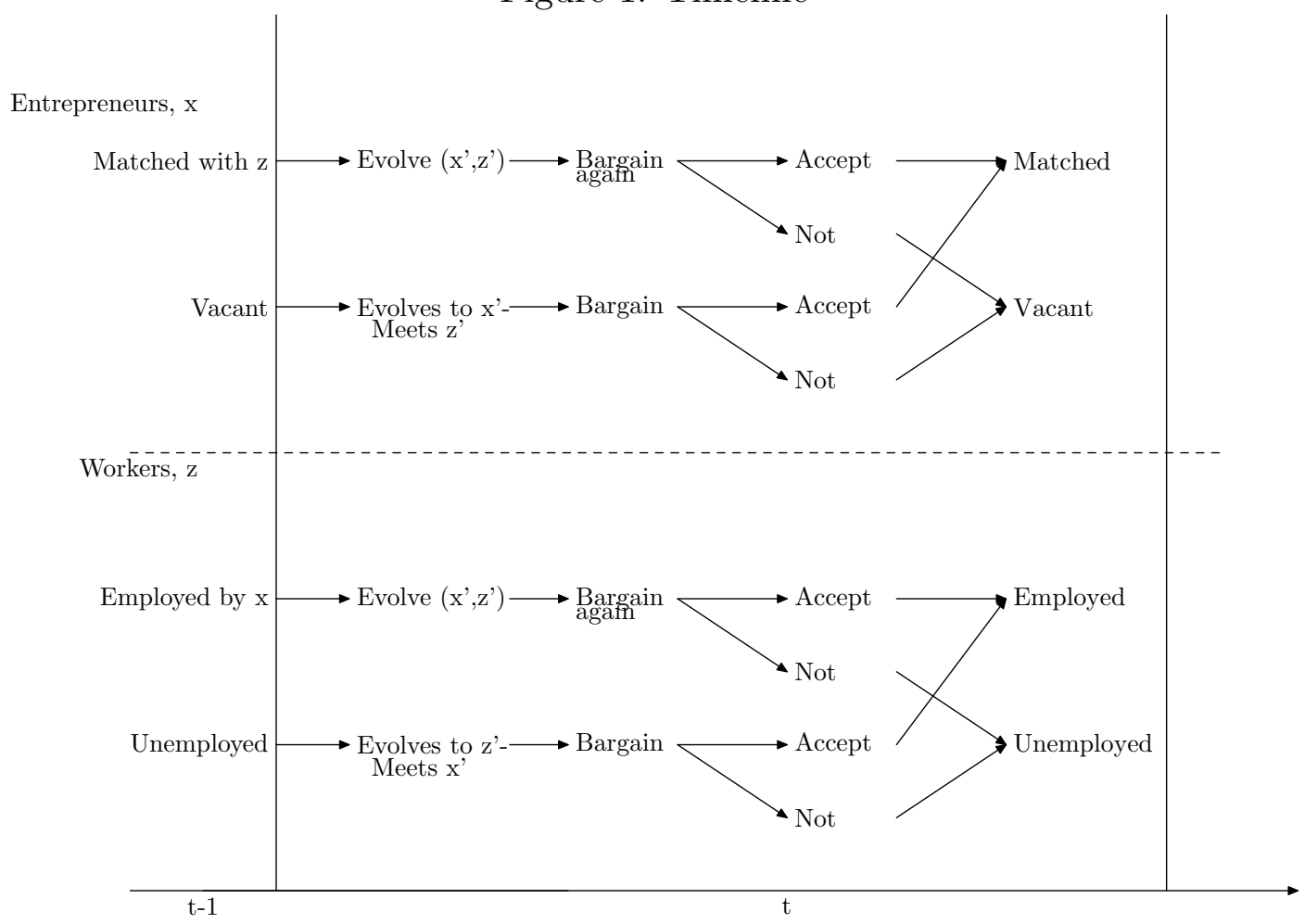




\section{$2.1 \quad$ Firms}

For a firm of type $x_{i}$, the value of a match with a $z_{k}$ worker, $P_{i k}$, is the momentary profit from production plus a continuation term. The value of remaining vacant is denoted by $V_{i}$. Formally, let $I_{i k}$ be an indicator function that takes value 1 in the situation where a worker of type $z_{k}$ and a firm of type $x_{i}$ both accept a match, and takes value 0 otherwise. If $w_{i k}$ is the wage agreed in case of an $(i, k)$ match and $F_{i k}$ is the production function, then

$$
P_{i k}=F_{i k}-w_{i k}+K_{i k}
$$

where $K_{i k}$ is the continuation value and is given by

$$
K_{i k}=\beta \sum_{j} \sum_{l} X(j \mid i) Z(l \mid k)\left(I_{j l} P_{j l}+\left(1-I_{j l}\right) V_{j}\right)
$$

This type of equation is used throughout the paper, and it is worth discussing at some length. It looks at an $(i, k)$ match. With probability $X(j \mid i)$ the type $x_{i}$ entrepreneur will evolve to type $x_{j}$ in the next period. Similarly, the worker will transit from $z_{k}$ to $z_{l}$ with probability $Z(l \mid k)$. At that point, knowing how types have evolved, the firm and the worker have to decide whether to remain matched or not. As stated above, the indicator function $I_{j k}$ is equal to 1 when both agree to remain matched, and 0 if either decides to quit. Hence, the term $I_{j l} P_{j l}$ is equal to 0 in the case of a layoff or a quit. It takes the value $P_{j l}$ of a productive match when parties agree to work together. The term $\left(1-I_{j l}\right) V_{j}$ is equal to the value of a vacancy when the match is not made (and $I_{j l}=0$ ). It is equal to the value of a match for the evolved pair $(j, l)$ in the opposite situation. The bottom line is that the term in parenthesis in (2) takes the value $P_{j l}$ for all $(j, l)$ pairs that engage in production and the value $V_{j}$ for all others.

A vacant firm has no current profit. Its founder discounts the expected net profit of possible encounters next period by a discount factor $\beta$. The current value of a vacancy is given by

$$
V_{i}=\beta \sum_{j} \sum_{k} X(j \mid i) \Omega_{k}\left(I_{j k} P_{j k}+\left(1-I_{j k}\right) V_{j}\right) .
$$


Here, once again, the indicator function serves the purpose of discarding the possible histories that do not take place given the solution of the Nash Bargaining problem.

\subsection{Workers}

When employed with a firm of type $x_{i}$, a type $k$ worker earns his bargained wage $w_{i k}$. All his earnings are taxed at rate $\tau$. Let $u(\cdot)$ be the worker's utility function. The value of being employed with a firm of type $x_{i}$ for a worker of type $z_{k}$ is

$$
E_{i k}=u\left(\left(w_{i k}\right)(1-\tau)\right)+L_{i k}
$$

where $L$ is the continuation value. It has a shape similar to the continuation value for firms:

$$
L_{i k}=\beta \sum_{j} \sum_{l} X(j \mid i) Z(l \mid k)\left(I_{j l} E_{j l}+\left(1-I_{j l}\right) U_{l}\right) .
$$

An unemployed worker collects unemployment benefits $b$ (possibly 0). He may engage in home production, $h$. The unemployed worker also pays taxes on unemployment benefits. In the following period, there is a probability that he meets an entrepreneur of a certain type and engages in production. The value of a match is given by $E(\cdot)$. The value function of an unemployed worker is given by

$$
U_{k}=u((b)(1-\tau)+h)+\beta \sum_{j} \sum_{k} Z(l \mid k) \Phi_{j}\left(I_{j l} E_{j l}+\left(1-I_{j l}\right) U_{l}\right) .
$$

\subsection{Nash Bargaining}

With their types known, workers and entrepreneurs bargain over wages. They then decide whether to accept or not the offer (and divorce if already matched). Assume they negotiate and end up with a Nash Bargaining solution. Thus, they choose the wage $w_{i k}$ to maximize

$$
\left[P\left(w_{i k}\right)-V_{i}\right]^{\xi} \times\left[E\left(w_{i k}\right)-U_{k}\right]^{(1-\xi)}
$$

In this equation, the value functions are made explicitly dependent on wages for exposition purposes. Given the outcome of wage bargaining, it is possible to compute the 
values $P\left(w_{i k}\right)$ and $E\left(w_{i k}\right)$ evaluated at the bargained wage $\hat{w}_{i k}$. The decision whether to accept the contract or not depends on whether $P\left(\hat{w}_{i k}\right)>V_{i}$ and $\left.E\left(\hat{w}_{i k}\right)\right)>U_{k}$ or not. It is now possible to define formally the indicator function $I_{i k}$. In doing so, define two other indicator functions, $I_{i k}^{f}$ and $I_{i k}^{w}$ :

$$
I_{i k}^{w}= \begin{cases}1 & \text { if } \left.E\left(\hat{w}_{i k}\right)\right)>U_{k} \\ 0 & \text { otherwise }\end{cases}
$$

and

$$
I_{i k}^{f}= \begin{cases}1 & \text { if } P\left(\hat{w}_{i k}\right)>V_{i} \\ 0 & \text { otherwise }\end{cases}
$$

The indicator of a match between an entrepreneur of type $x_{i}$ and a worker of type $z_{k}$ is then $I_{i k}=I_{i k}^{w} I_{i k}^{f}$.

\subsection{Stationary Matching Probabilities}

All is now in hand to compute the probabilities of meeting workers or firms of certain type. How can a firm of type $x_{i}$ end up looking for a worker? It must not have been matched in the previous period. To be in such a position, either it experienced a split last period, or it didn't contract. In any case, it was not productive in the previous period. For a worker, the situation is similar: either he was matched in the previous period and remains matched, or he found a job that suits him and for which he is suitable. To compute these probabilities, it is useful to obtain the proportion of matches of type $(i, k)$ and the proportion of pairs $(i, k)$ that ended up not matching, either because of a fire/quit decision, or because they were not well suited for each other. For now, it is assumed that all unmatched workers and all unmatched firms meet a potential partner at the beginning of the period.

Let $M_{i k}$ be the proportion of matches of type $(i, k)$ at the beginning of a period. Let $N$ be the measure of workers and firms who decided not to contract. Remember that $\Phi$ and $\Omega$ sum up the distributions of available firms and workers. These distributions evolve according to the law of motions defined by the following 4 equations (or rather 
$m \times n+m+n+1$ equations, as each holds for every possible $(i),(k))$ or $(i, k))$ :

$$
\begin{aligned}
& \qquad M_{i k}^{\prime}=\sum_{j} \sum_{l}\left(M_{j l}+\Phi_{j} \Omega_{l} N\right) I_{j l} X(i \mid j) Z(k \mid l), \\
& N^{\prime}=\text { total measure firms }-\sum_{i} \sum_{k} M_{i k}^{\prime} \\
& \\
& =\text { total measure workers }-\sum_{k} \sum_{i} M_{i k}^{\prime} .
\end{aligned}
$$

Finally,

$$
\Phi_{i}^{\prime}=\frac{\sum_{j} \sum_{l}\left(M_{j l}+\Phi_{j} \Omega_{l} N\right)\left(1-I_{j l}\right) X(i \mid j)}{\sum_{i} \sum_{j} \sum_{l}\left(M_{j l}+\Phi_{j} \Omega_{l} N\right)\left(1-I_{j l}\right) X(i \mid j)},
$$

and

$$
\Omega_{k}^{\prime}=\frac{\sum_{j} \sum_{l}\left(M_{j l}+\Phi_{j} \Omega_{l} N\right)\left(1-I_{j l}\right) Z(k \mid l)}{\sum_{k} \sum_{j} \sum_{l}\left(M_{j l}+\Phi_{j} \Omega_{l} N\right)\left(1-I_{j l}\right) Z(k \mid l)} .
$$

These equations amount to counting agents. At the beginning of the period, there are $M_{j l}$ pairs $j l$ already matched. In addition, there are $\Phi_{j} \Omega_{l} N$ pairs $j l$ that just met. All these bargain over wages, and decide whether to accept the contract or not. If they do, $I_{j l}=1$. These $j l$ pairs then evolve to types $i k$ with transition probabilities $X(i \mid j)$ and $Z(k \mid l)$. Summing over $j$ and $l$ yields the number of pairs $i k$ that are matched at the beginning of the new period, as given by (10). The number of unmatched agents, taking into account that there are the same number of firms and workers, is the mass of agents less the sum of all matched agents. The number of firms of type $i$ (respectively a workers of type $k$ ) that aren't matched is obtained by adding up the firms (resp., workers) that didn't match in the previous period, and evolved to $i$ (resp., $k$ ). ${ }^{2}$ To obtain the probability of meeting a type $i$ firm, it is necessary to divide this by the total number of unmatched firms. A similar operation yields the probability of meeting a worker of type $k$.

\footnotetext{
${ }^{2}$ If the number of firms and workers differ, then the second equality in (11) does not hold. In that case, it is necessary to compute the number of unemployed firms and worker independently, replacing $\mathrm{N}$ everywhere by the new values wherever appropriate.
} 


\subsection{Government}

To complete the model, aggregate variables have to be defined. There are two possible variables that depend on aggregates, $\tau$ and $b$, but the two are linked through the government budget constraint $(\tau, b)$. In the rest of the paper, $b$ is taken as a parameter and $\tau$ is given by the assumption that the government keeps a balanced budget. The government taxes every worker at rate $\tau$, and distributes the tax revenue to the unemployed. The government budget constraint is

$$
\begin{aligned}
\sum_{i} \sum_{k}\left(M_{i k}+\Phi_{i} \Omega_{k} N\right)\left(1-I_{i k}\right) b \tau+\left(M_{i k}+\Phi_{i} \Omega_{k} N\right) I_{i k} w_{i k} \tau & \\
& =\sum_{i} \sum_{k}\left(M_{i k}+\Phi_{i} \Omega_{k} N\right)\left(1-I_{i k}\right) b .
\end{aligned}
$$

In (14), the left-hand side is the total government receipts, composed of the tax on unemployed (first block) and the tax on employed. The right-hand side represents the unemployment insurance benefits paid out.

\subsection{Equilibrium}

It is now possible to define a stationary equilibrium.

Definition 1 A stationary matching equilibrium can be represented by a set of value functions for matched and unmatched agents, $E, P, U, V$, by wage rule $w$, by policy and aggregate variables $\tau$, by indicator functions $I^{f}$ and $I^{w}$, and by matching probabilities $\Phi$ and $\Omega$ such that:

1. Value functions are given by (1), (3), (4) and (6).

2. The wage rule solves the Nash Bargaining problem (7), and the indicator functions are set following the rules (8) and (9).

3. Matching probabilities follow the stationary distribution given by (10),(12) and (13).

4. The government keeps a balanced budget, so that (14) holds. 
Solving the model involves solving a fixed point problem: the indicator functions depend on the stationary probabilities and the indicator functions, the probabilities depend on the probabilities and the indicator functions. Not much about the equilibrium can be said analytically. The rest of the equilibrium analysis turns to numerical simulations. The algorithm used to solve for the stationary equilibrium is very similar to the one described in Greenwood, Guner, and Knowles (2003). It is twisted just slightly to allow for infinitely-lived agents.

\section{Results: A First Look}

In this section, a first glance at the results is given. The discussion centers on the matching sets (who matches with whom) and prepares us for a comparison with the optimal solution. In the competitive setting, workers and firms meet and bargain over wages (following a Nash Bargaining scheme). They take into account their outside options. For an entrepreneur, refusing a match in the current period results in no production, hence no income, and the chance to meet a better, or worse, type of worker in the next period. For a worker, there is the possibility of engaging in home production. Home production is not skill-specific. Hence one expects better workers to be less influenced by it.

The production function is assumed to be of the type

$$
F_{i k}=\frac{\left(\alpha x_{i}^{\frac{1}{1-\rho}}+(1-\alpha) z_{k}^{\frac{1}{1-\rho}}\right)^{(1-\rho)}}{(1-\rho)} .
$$

Here, $\rho$ is a parameter that determines the degree of complementarity between entrepreneur and worker skills. Workers are assumed to have utility function $u(c)=c^{\sigma}$, where $\sigma$ is the coefficient of risk-aversion.

Two different economies are discussed in this section: the economy with an additive production function $(\rho=0)$, and the one with a Cobb-Douglas production function $(\rho=1)$. In the former economy, skills are perfect substitute. The second one is more interesting, and probably closer to the real world. It seems natural to assume that skills are complements. Someone that didn't finish high school is not going to fare 
well at an engineering firm, and is going to do a lot worse than someone that studied engineering. ${ }^{3}$ It is not so easy, however, for certain jobs, to match degrees with skills. The first economy is worthwhile discussing, however, because it helps illustrate the mechanics of the model.

There are three preference parameters $(\beta, \sigma$ and $h)$, two production parameters ( $\alpha$ and $\rho$ ), the bargaining weight $\xi$, and the idiosyncratic shocks to set. The Markov matrices guiding the shocks can be viewed as approximations to AR processes, following Tauchen (1986). In that case, they are parameterized by a persistence element (say $\gamma$ ) and a deviation parameter (say $\epsilon$ ). The parameters for the idiosyncratic shock to workers' types are chosen so that the proportion of workers of various skills and the hazard rate in the model matches US data. More precisely, workers are separated into four categories: less than high-school $(n=1,2)$, high school and some college $(n=3,4,5,6)$, college graduate $(n=7,8)$, and more than college graduate $(n=9,10)$. The parameters defining the Markov matrices are chosen so that the percentage of the labor force in each category is close to that in the data, and the percentage of unemployed by various unemployment duration are roughly consistent to those in the US data.

Since the lowest duration category is 'less than 5 weeks', one period in the model is taken to be of half that length, i.e. 2.5 weeks. The period length, together with the level of the interest rate, then dictates the choice of the discount factor $\beta$. If the annual interest rate is $4 \%-6 \%$, the discount factor must be an is $\beta=.997$. In the benchmark scenario, workers are assumed to have log-utility $(\sigma=0)$. This is the lower bound for risk aversion in standard models of the aggregate economy. The importance of the standard assumption of a risk-neutral world is evaluated at a later stage. Home production, $h$ is set arbitrarily to keep the production set in the shape depicted in Figure 2. The benchmark parameters can be found in Table 1. Equal-

\footnotetext{
${ }^{3}$ Many papers in the literature assume that low-types cannot produce in high-skill firms (see, for instance Albrecht and Vroman (2002)). This assumption is examined in a later section.
} 
Figure 2: Production Set

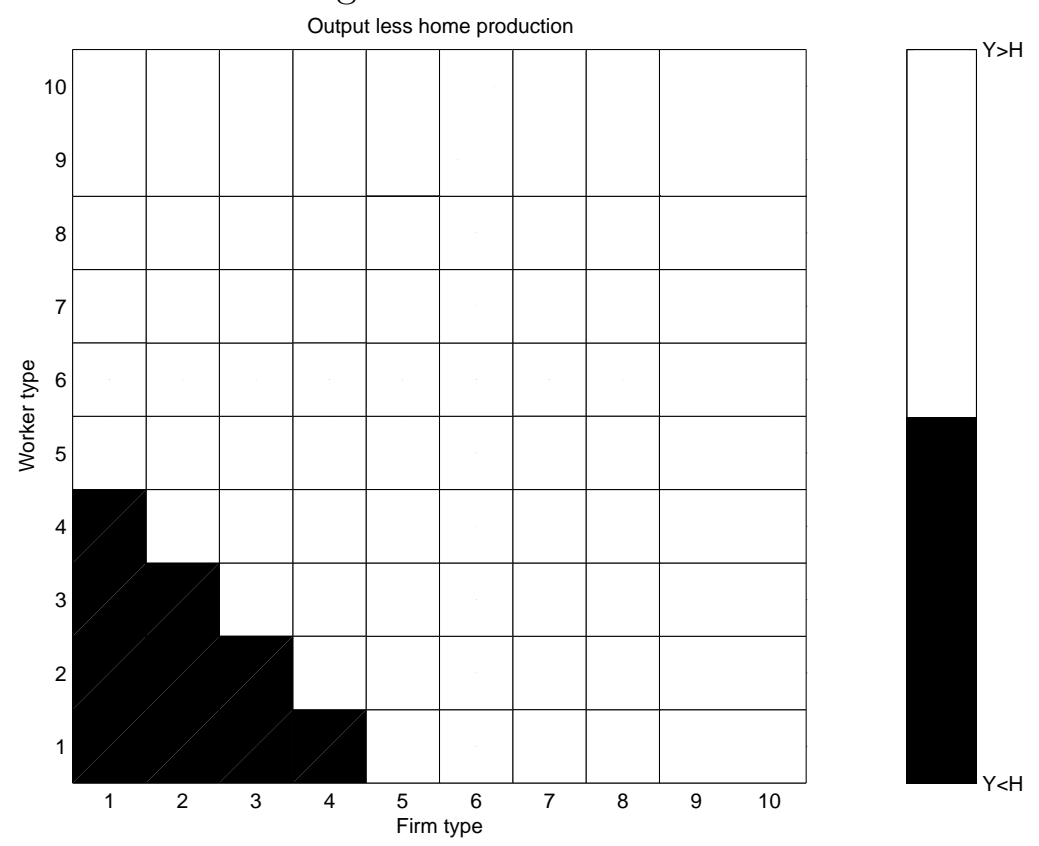

weight bargaining is assumed, and the weight are normalized to 1 for simplicity. By

Table 1: Benchmark Parameters

\begin{tabular}{|l|l|}
\hline Parameter & Value \\
\hline \hline$\beta$ & .997 \\
\hline$\alpha$ & .5 \\
\hline$\sigma$ & 1 \\
\hline$\rho$ & 0 or 1 \\
\hline$h$ & .17 \\
\hline$b$ & 0 \\
\hline
\end{tabular}

design, the distribution of education level in the model matches that in the US data (Census 2002), as can be seen in Table 2.

\subsection{Additive Economy}

In the additive economy, skills are perfect substitute. Both parts of a potential match contribute exactly their skill to the match. One can thus expect it to be easier to match. Assume for a while that skills do not evolve: a type-x agent remains of that type forever. Assume in addition that agents only take the current period into account. 
Table 2: Education in US Data and in the Model

\begin{tabular}{|l|l|c|}
\hline Education & US & Benchmark \\
\hline \hline Less than High School & $10.1 \%$ & $10 \%$ \\
\hline High School and Some College & $59.6 \%$ & $56 \%$ \\
\hline College & $20.0 \%$ & $24 \%$ \\
\hline More than College & $10.2 \%$ & $10 \%$ \\
\hline
\end{tabular}

Source: Bureau of Labor Statistics, 2001.

In this case, all entrepreneurs want to match as long as production is positive, since their outside option is nil. Workers, on the other hand, can get some positive utility from home production. The outcome of the bargaining process is easy to see in this alternative economy. All pairs that produce more than the level of home production match, and others don't. Workers are able to extort most of the surplus.

If skills are constant, but agents live in a dynamic world, another consideration kicks in. By foregoing production (or income) today, an agent can hope for a better match next period. Pairs that produce less than the level of home production will never match. But in such a world, some viable pairs, in that sense, could also decide not to match.

The final step to arrive at the model described above is to let skills evolve over time. An $(x, z)$ pair evolves to $\left(x^{\prime}, z^{\prime}\right)$ with a certain probability. Even if the pair cannot produce more than the level of home production today, it may have a high enough probability to evolve to a worthwhile pair next period. It is then possible that both agents decide to accept the match. The production level, net of the level of household production, pair by pair, can be seen in the top part of Figure 3. The lower-left side of the square, with the dark shade, contains all the pairs that do not produce more than the level of household production. The matching set is represented in the lower part of Figure 3. In this graph, a dark shade corresponds to a no match decision. Notice that some pairs that produce less than $h$ match.

Output in this economy is 2.56 , with an average wage of 2.17 and standard deviation 0.97. This implies that the labor share of income is $54 \%$. The maximum wage is 5.7 and the minimum one is 0.13 , which is below the level of household production, $\mathrm{h}=.17$. The 
Figure 3: Production Levels and Matching Set, $\rho=0, \beta=.997$
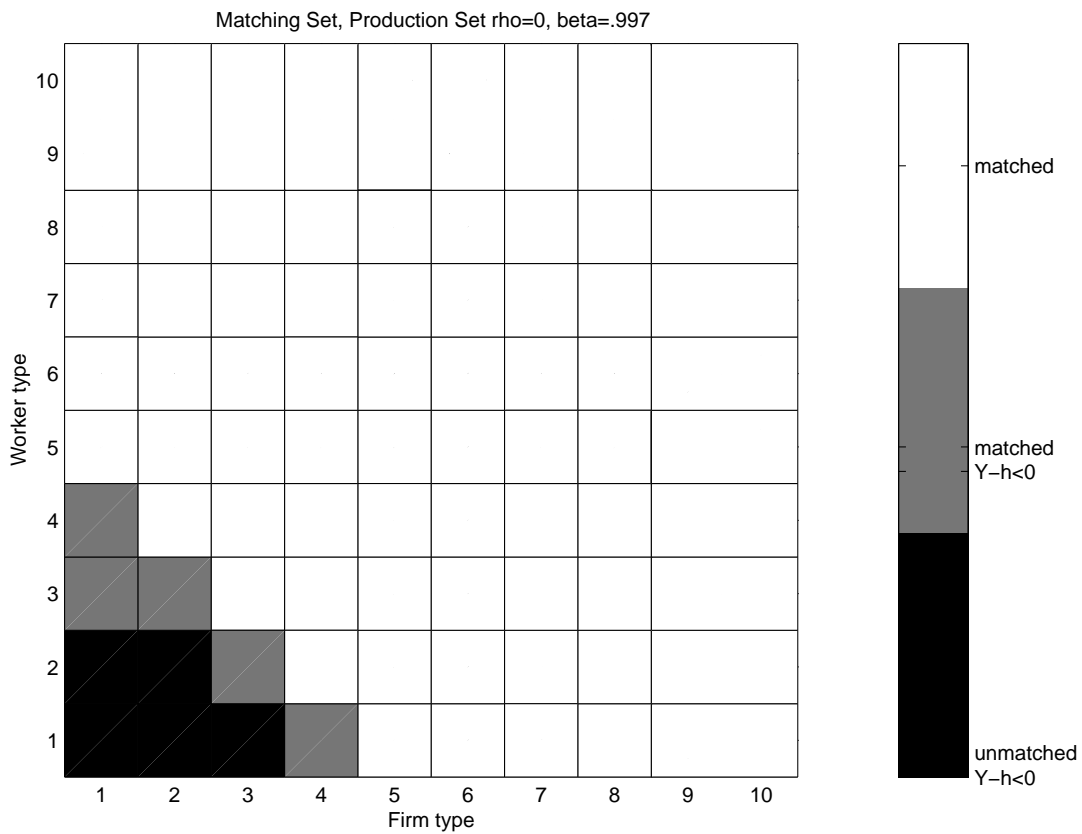

unemployment rate is $1.7 \%$. It is concentrated in the lower end of the skill distribution. Workers of the lowest types are more likely to be unemployed and when they are they spend on average 2.62 and 2.01 periods unemployed. The Gini coefficient for earnings is 0.49

When skills are perfect substitutes, the first-best level of output, defined as the one that would occur in a frictionless world, is just the full employment level of output. This is simple to see. The production function is now just the sum of the two types in the pair, equally weighted. From an aggregate perspective, every individual contributes his type to total output, and it doesn't matter if a high type is matched with a low type. There is no cost of mismatch to society. This is not the case when there are complementarities in skills. It is therefore useful to have a measure of the degree of mismatch in the economy. The most straightforward such measure is the sum squared difference of ranks, which can be shown to be closely related to rank-correlation, but is much easier to compute in the model at hand. The expression for it is

$$
D^{* *}=\frac{\sum_{i} \sum_{k}(i-k)^{2} M\left(x_{i}, z_{k}\right)}{\max (|i-k|)^{2}} \cdot
$$

\footnotetext{
${ }^{4}$ The scaling term $\max (|i-k|)^{2}$ does not belong to the original definition of sum squared
} 
Notice that $0 \leq D^{* *} \leq 1$, with $D^{* *}=0$ meaning perfect sorting. In the benchmark model with substitutable skills, $D^{* *}=0.132$.

Although in the additive economy the first-best level of output is just the one at full employment, this is not the case when the production function is Cobb-Douglas. In the later situation, mismatch is costly. If agents can be matched at will, the ideal configuration is to have perfect sorting. Let $\Psi^{f}\left(x_{i}\right)$ and $\Psi^{w}\left(z_{l}\right)$ denote the stationary distributions of firms and workers. Since it is assumed that there is the same number of types of workers and firms, and since the processes guiding types are identical, these two distributions are identical. Let $\Psi(i)$ denote the measure of type $i$ firms and workers in the economy. The first-best level of output is given by

$$
Y^{f b}=\sum_{i} \Psi(i) F\left(x_{i}, z_{i}\right)
$$

Alternatively, it might be desirable to take into account the level of home production, h. In that case, the first-best level of output is given by

$$
Y_{h}^{f b}=\sum_{i} \Psi(i)\left(F\left(x_{i}, z_{i}\right) I^{h}\left(x_{i}, z_{i}\right)+\left(1-I^{h}\left(x_{i}, z_{i}\right)\right) h\right)
$$

where $I^{h}$ is an indicator function that takes value 1 if the pair can produce above h, and 0 otherwise.

These measures are valid if there is the same number of workers and firms of each type. When this is not the case, there is presumably some ladder effect. For instance, if there are more workers than firms, the excess of high type workers should be matched with the second-best firms. The first-best level of output $\left(Y^{f b}\right)$, which is equal to the full employment level of output in the case at hand, is 2.562. Since the equilibrium level of output is 2.560 , unemployment in this world is not very costly. Only the very low productivity pairs do not match. The first-best level of output when only pairs producing more than $\mathrm{h}$ are active $\left(Y_{h}^{f b}\right)$ is lower than the actual level. Obviously, this changes if home production is included in the measure of actual output.

It is possible to compute the level of output with perfect sorting at the current level of unemployment. Imagine a planner who can ensure that people meet their perfect difference. 
counterparts, but cannot force a match to take place if outside options are worth more. Note that there is not necessarily the same number of firms and workers of a given type. ${ }^{5}$ Hence, for there to be exactly the same level of unemployment in the measure of sorted output, some spreading down must be introduced. Implementing a way to take that into account is messy. It is possible, instead, to compute an upper and a lower bound of sorted output. To do this, a measure of how many workers and firms of each type are matched is needed. To obtain the number of matched firms and workers of each type, sum the measure of matches $M(x, z)$ over worker (to get the number of matched firms of each type) and firms (to get the number of matched workers of each type). Formally, define

$$
\begin{array}{r}
P_{x}(i)=\operatorname{Pr}(\operatorname{rank}(x)=i)=\sum_{l} M\left(x_{i}, z_{l}\right) \text { and } \\
P_{z}(l)=\operatorname{Pr}(\operatorname{rank}(z)=l)=\sum_{i} M\left(x_{i}, z_{l}\right),
\end{array}
$$

where $P_{x}(i)$ denotes the mass of matched firms of type $i$, and $P_{z}(l)$ denotes the mass of matched workers of type $l$. If the equilibrium is not symmetric, which is the case when there are complementarities in the production function, these two measures are not equal. Then sorted output is between a lower bound

$$
Y_{l b}^{\mathrm{sort}}=\sum_{i} F\left(x_{i}, z_{k}\right) \min \left(P_{x}(i), P_{z}(i)\right)
$$

which exaggerates the importance of unemployment, and an upper bound

$$
Y_{u b}^{\mathrm{sort}}=\sum_{i} F\left(x_{i}, z_{k}\right) \max \left(P_{x}(i), P_{z}(i)\right)
$$

In the model with an additive production function, it is the case that $Y_{u b}^{\text {sort }}=Y_{l b}^{\text {sort }}=Y$. This confirms the intuition that mismatch does not matter in this economy. It is possible to define levels of sorted output, taking into account whether pairs produce more than home production by defining $Y_{l b}^{\text {sort }, h}$ and $Y_{u b}^{\text {sort }, h}$ similarly to (17). These are just slightly lower.

\footnotetext{
${ }^{5}$ This is due to the difference in risk aversion between firms and workers.
} 


\subsection{Cobb-Douglas Economy}

When skills enter as complements in the production function, a new effect sets in. The returns to matching with a similarly skilled agent are more than proportional. In other words, mismatch is costly. The production function net of home production can be seen in the top panel of Figure 4. Again, the lower left corner of the graph, in dark, holds the pairs that produce less than home production.

In a static model, one expects these pairs not to match, since workers can get more by staying at home, and all other pairs to match, as they can split the surplus advantageously to both. In the dynamic model, this is not the case, however. This is confirmed by the lower panel of Figure 4, which represents the equilibrium matching set. A number of pairs that can produce more than the level of home production do not match. These agents are hoping to get a significantly better match next time around. Note that, contrary to the additive case, no pair that potentially produces less than home production matches.

Figure 4: Production Levels and Matching Set, $\rho=1, \beta=.997$

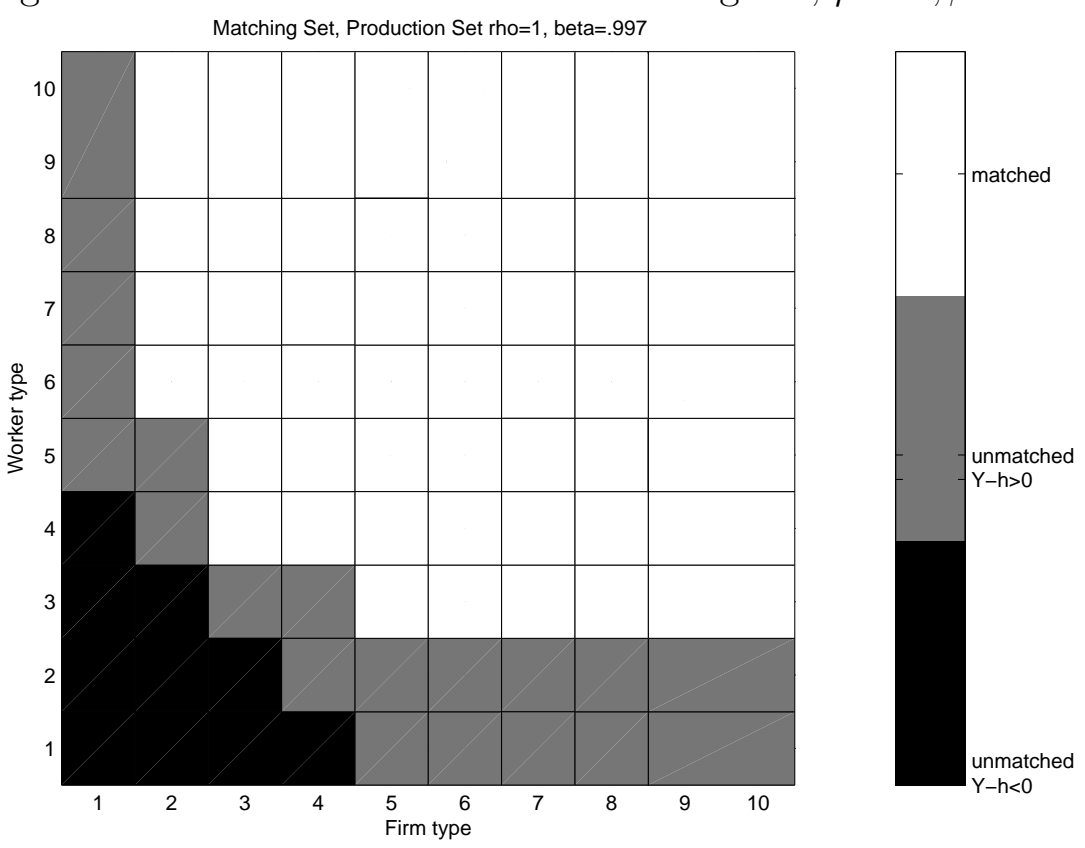

Output in this version of the economy is 1.79 , compared to a first-best level of 2.78 (when $\mathrm{h}$ is taken into account, the first-best level of output is 2.77). The unemployment 
rate is high at $16.7 \%$. Low-skilled unemployment is extremely high in this economy. For workers of type 1 and type 2, the length of unemployment is 16.8 and 5.2 periods on average, respectively. The upper bound for sorted output at the current unemployment level is 2.73. The lower bound is 2.64. This indicates that unemployment causes a loss of between $\frac{2.78-2.73}{2.78} \cdot 100=17.9 \%$ and $\frac{2.78-2.64}{2.78} \cdot 100=5.0 \%$ in output. Costs due to mismatch are between $\frac{2.73-1.79}{2.78} \cdot 100=33.8 \%$ and $\frac{2.64-1.79}{2.78} \cdot 100=30.6 \%$. Hence, in the economy with skill complementarity, the cost of mismatch is a lot greater than the cost of unemployment. Mismatch, however, is lower than in the additive case, at 0.084. The average wage is 1.79 , which implies a labor share of income of $55 \%$. The standard deviation of wages is 1.3. The Gini coefficient on earnings stands at 0.509. The maximum wage is 5.53 and the minimum one is 0.13 , which is below the level of home-production.

\section{Planner's Problem}

Is the equilibrium decision rule optimal in the economy? Assume the objective is to maximize the expected present value of output. A productive match contributes output today, and possibly in the following periods. Who is matched and who isn't also affects the composition of searchers. If skills are complementary, it is preferable that high skills meet with high skills. Hence, one can expect that a planner who can choose and enforce a matching rule for the economy, wants low skill pairs to produce, thus increasing slightly output today, but more importantly increasing the likelihood of high skill pairs forming in the future. The planner also prefers that high-skilled lowskilled pairs do not form, especially if the probability that some sorting occurs in the future is high. If skills are perfect substitutes, then each member of a pair contributes exactly his skill, no matter what the value of the other party. It is then obvious that the highest possible present value of output is achieved when all matches produce. ${ }^{6}$

\footnotetext{
${ }^{6}$ The planner is restricted to stationary decision rules. It would be interesting to check whether non-stationary rules can fare better, as in Shimer and Smith (2000), but this is left for future research.
} 
The purpose of this section is to check if this intuition holds true.

Assume the existence of a planner/dictator. The planner can force agents in the economy to act at her will. She chooses a matching rule $I$ in order to maximize the expected discounted sum of output. ${ }^{7}$ In what follows, a " ' " denotes next period variables, and a "0" denotes the initial probability distribution. In addition, since some functions depend on future distributions, and these depend on today's decision rule, let $\mathcal{F}^{\prime}(I)$ represent the future distributions of matched pairs as well as searchers. ${ }^{8}$ It enters as an argument in appropriate functions. Note that next period's probability distribution depends not only on today's decision rule, but also on today's probability distribution.

The planner is assumed to maximize the present value of output, $O(I)$. This can be stated in sequential fashion:

$$
O(I) \equiv \max _{\left\{I_{t}\right\}} \sum_{t=0}^{\infty} \beta^{t}\left\{\sum_{i} \sum_{k}\left(M_{i k, t}+\Phi_{i, t} \Omega_{k, t} N_{t}\right)\left(I_{i k, t} F_{i k}+\left(1-I_{i k, t}\right) h\right)\right\},
$$

with the distributions evolving according to $(10),(12),(13)$. This is just the infinite discounted sum of output, where the planner takes home production into account. In recursive notation, the problem is

$$
W(\mathcal{F})=\max _{I} \sum_{i} \sum_{k}\left[\left(M_{i k}+\Phi_{i} \Omega_{k} N\right)\left(I_{i k} F_{i k}+\left(1-I_{i k}\right) h\right)\right]+\beta W\left(\mathcal{F}^{\prime}(I)\right),
$$

with $\mathcal{F}^{\prime}(I)$ determined by (10), (12) and (13) once again. This problem is complicated to solve numerically. A big difference between the planner's objective and the individual's is that the planner takes the effect of the current decision rule on the future distributions into account. Including this feature in the computation increases the dimensionality of the problem, rendering the usual methods impractical.

In Section 4.2, a method is put forward to solve for the stationary optimal decision rule. An easier problem is solved first. This problem is analogous to finding the Golden Rule in the neoclassical growth model. It is useful for two reasons. It helps illustrate a step of the algorithm outlined in the following section; and it serves as a consistency

\footnotetext{
${ }^{7}$ The planner is not allowed to choose mixed-strategies.

${ }^{8}$ Formally, $\mathcal{F}^{\prime}(I) \equiv\left(\Omega^{\prime}, \Phi^{\prime}, M^{\prime}, N^{\prime}\right)$, which all depend on $I$.
} 
check: as the discount factor approaches 1, the optimal decision rule should tend to the 'Golden' decision rule.

\subsection{The Golden Matching Rule}

Assume first that the planner tries to maximize steady state consumption. This amounts to maximizing steady-state output. The planner is trying to solve for what can be called, by analogy with the neoclassical growth model, the Golden Matching Rule. It is important to understand that this does not amount to solving for the optimal stationary decision rule. It is interesting to discuss this case for two reasons. First, as a reference point: the Golden Matching Rule should be the limit of the Optimal rule as the discount factor, $\beta$, converges to 1 . Second, for methodological reasons: one of the steps in the algorithm proposed to solve for the optimal decision rule mimics closely the algorithm used to find the Golden Matching Rule.

The planner chooses $I$ to maximize

$$
y(I)=\sum_{i} \sum_{k}\left[\left(M_{i k}^{*}+\Phi_{i}^{*} \Omega_{k}^{*} N^{*}\right)\left(I_{i k} F_{i k}+\left(1-I_{i k}\right) h\right)\right],
$$

where a "*" denotes the steady-state distribution. The steady-state distributions are given by

$$
\begin{gathered}
\qquad M_{i k}^{*}=\sum_{j} \sum_{l}\left(M_{j l}^{*}+\Phi_{j}^{*} \Omega_{l}^{*} N^{*}\right) I_{j l} X(i \mid j) Z(k \mid l), \\
N^{*}=\text { total measure firms }-\sum_{i} \sum_{k} M_{i k}^{*} \\
=\text { total measure workers }-\sum_{k} \sum_{i} M_{i k}^{*} .
\end{gathered}
$$

Finally,

$$
\Phi_{=}^{*} \frac{\sum_{j} \sum_{l}\left(M_{j l}^{*}+\Phi_{j}^{*} \Omega_{l}^{*} N^{*}\right)\left(1-I_{j l}\right) X(i \mid j)}{\sum_{i} \sum_{j} \sum_{l}\left(M_{j l}^{*}+\Phi_{j}^{*} \Omega_{l}^{*} N^{*}\right)\left(1-I_{j l}\right) X(i \mid j)},
$$

and

$$
\Omega^{*}\left(z_{k}\right)=\frac{\sum_{j} \sum_{l}\left(M_{j l}^{*}+\Phi_{j}^{*} \Omega_{l}^{*} N^{*}\right)\left(1-I_{j l}\right) Z(k \mid l)}{\sum_{k} \sum_{j} \sum_{l}\left(M_{j l}^{*}+\Phi_{j}^{*} \Omega_{l}^{*} N^{*}\right)\left(1-I_{j l}\right) Z(k \mid l)} .
$$

These equations are similar to equations (10)-(13) evaluated at the steady state. 


\subsubsection{Solving for the Golden Matching Rule}

Solving for the golden-rule is conceptually not difficult. Notice that the stationary distribution depends only on the decision rule. Hence, for every possible decision rule, it is possible to iterate on equations (10)-(13) until a fixed point is found. One can then plug back the stationary distribution in the expression for the steady-state output, equation (24), to obtain the steady-state output associated with the decision rule, $y(I)$. The Golden Matching Rule is just the decision rule that yields the maximum output: $I^{G R}: y\left(I^{G R}\right) \geq y(I), \forall I$.

Computationally, there is one problem. Since the matching rule is a $n \times m$ matrix with zeros and ones, there are $2^{m n}$ possible decision rules. The method outlined above involves searching over the whole space of decision rules to find the one maximizing the objective. While the method is feasible for $m=n=4$, it is not so for $m=n=10$. There are two routes around this problem. The first route involves reducing the space on which the search is performed using the researcher's knowledge of the problem. For instance, by looking at the production function in the numerical examples above, one notices it is symmetric. An $i k$-pair produces the same as a $k i$ one. This implies that the Golden Matching Rule must be symmetric: if it is worthwhile having the $i k$-pair produce, it is also worthwhile having the $k i$-pair do so. In addition, there is some monotonicity to the problem. If a firm matches with a worker of type $k$, and doesn't with one of type $k-1$, then it is never the case that the firm matches with a worker of type $k-2$ and doesn't match with one of type $k+1$.

The second route is less ad-hoc. The problem at hand is particularly well suited for Genetic Algorithms. The original strand of research in Genetic Algorithms uses chromosomes defined as vectors of genes taking values of 1 and 0 . The difficulty, when using Genetic Algorithms, is to encode the variables in such chromosomes. Here, that step is superfluous: the decision variable is naturally coded. ${ }^{9}$

\footnotetext{
${ }^{9}$ See Goldberg (1989) and the references therein for details.
} 


\subsection{Finding the Optimal Steady-State Matching Rule}

As stated before, solving the planner's problem with usual dynamic programming tools is not practical. It involves keeping track of the effect of today's decision on the future distribution, which affects future decisions and distributions. The idea for dealing with this is as follows. Assume the economy is in a certain state, described by initial distributions $\mathcal{F}_{0}$. Assume the planner cannot reoptimize in every period: she chooses the decision rule $I$ once and for all. Associated with that decision rule are stationary distributions $\mathcal{F}^{*}(I)$, and present value of output $O\left(I, \mathcal{F}_{0}\right)$. Taking inspiration from the algorithm used to find the Golden Matching Rule, it is possible to isolate the decision rule that yields the highest present value of output, given initial distribution $\mathcal{F}_{0}$. Call it $\widehat{I}$. This procedure does not, in general, land the optimal stationary decision rule. There is a case, however, when it does. If the stationary distribution associated with $\widehat{I}$ is the same as the initial distribution, so that $\mathcal{F}^{*}(\widehat{I})=\mathcal{F}_{0}, \widehat{I}$ is the optimal stationary decision rule. When this is not the case, the idea is to use the latter stationary distribution as an initial condition in the next iteration of the algorithm.

It is worth describing the method, as it is applied to this model, in some detail. First, letting $I$ denote the planner's choice, and $\mathcal{F}$ summarize the distributions, the expected present value of output can be rewritten as

$$
O(I)=\sum_{i} \sum_{k}\left[\mathcal{F}_{i k, 0} I_{i k} F_{i k}\right]+\beta G\left(\mathcal{F}^{*}(I)\right)
$$

where

$$
G\left(\mathcal{F}^{*}(I)\right)=\sum_{j} \sum_{l}\left[\mathcal{F}_{j l}^{*}(I) I_{j l} F_{j l}\right]+\beta G\left(\mathcal{F}^{*}(I)\right)
$$

and $\mathcal{F}^{*}$ is given by $(25),(27)$ and (28), as when solving for the Golden Matching Rule. ${ }^{10}$ In the expression for the continuation value, the dependence on the decision rule is made clear. To solve the planner's problem, the idea is to work with these equations repeatedly. The algorithm proceeds as follows:

\footnotetext{
${ }^{10}$ By abuse of notation, $\mathcal{F}_{i k, 0}=M_{i k, 0}+\Phi_{i, 0} \Omega_{k, 0} N_{0}$ and $\mathcal{F}_{i k}(I)=M_{i k}+\Phi_{i} \Omega_{k} N$, where the dependence on the decision is made explicit.
} 
1. Start with initial distributions $\mathcal{F}_{0}$, and a guess for the continuation value, $G_{0}$.

2. For all possible decision rules $I$ :

(a) Iterate on the equations giving the distributions, (10),(12), and (13) to obtain the stationary distribution associated with the decision rule, $\mathcal{F}(I)$.

(b) Using the distributions obtained in the previous step and the guess for the continuation value, $G_{0}$, iterate on (30) until $G(\mathcal{F}(I))$ is obtained.

(c) Plug $I, \mathcal{F}(I)$ and $G(\mathcal{F}(I))$ into the expression for the present value of output, (29), to get the present value of output associated with the current decision rule, $y(I)$.

3. Of all possible decision rules, pick the one, labelled $\widehat{I}$, that yields the maximum present value of output: $\widehat{I}: y(\widehat{I}) \geq y(I), \forall I$. Relabel the associated distributions $\mathcal{F}^{1}$ and the associated continuation value $G^{1}$.

4. If $\left|\mathcal{F}^{1}-\mathcal{F}_{0}\right|<\epsilon$, end the algorithm. Otherwise, use $\mathcal{F}^{1}$ and $G^{1}$ as initial condition and start again in step 2. Repeat until $\left|\mathcal{F}^{j+1}-\mathcal{F}^{j}\right|<\epsilon$, where $j+1$ is the number of the current iteration.

\subsection{Results}

The optimal steady-state decision rule is very different from the equilibrium decision rule. It is depicted in Figures 5 (additive production) and 6 (Cobb-Douglas production) for the parametrization used in the previous section. ${ }^{11}$ In the additive case, as expected, the planner just wishes everyone to match. In the complementarity case, a match today has two effects, which are both taken into account by the planner. First, it increases output today. Second, it affects the distribution of searchers in the future. The planner

\footnotetext{
${ }^{11}$ The darker areas in this figure indicates pairs that are never matched. The white area identifies pairs that are matched both in the optimum and in the equilibrium. The gray areas indicate pairs that are matched in either the optimum (light gray) or the equilibrium (dark gray) but not in both.
} 
seeks to increase the quality of the remaining pool by choosing wisely who accepts whom. When an unskilled worker and a low-quality firm meet, it is unambiguously better to have them match. This creates some extra output, and this increases the quality of the pool of searchers. If very different agents meet, then there is a tradeoff between present and future production. Matching today yields an immediate increase in output. But the chance of a better match is higher, since lower matches are forced to match together. A very skilled worker should not match with a low-quality firm: the extra output today is small compared with the expected increase in output if he is matched to a high-quality firm next period, given that the chances of meeting high type are increased.

This, of course, is true for the case where a high quality firm and a low skilled worker meet. Perfect sorting is not optimal, however, as the loss in present output from allowing only identical types to match more than cancels out the possible gain in future output. Notice that it is optimal to have pairs that produce less than home production to match. The externality they impose by not matching is more costly than the additional 'output' gained by producing at home. These pairs presumably would be induced to exit the market altogether, were this allowed.

Figure 5: Matching Rule, Equilibrium and Optimum, $\rho=0, \beta=.997$

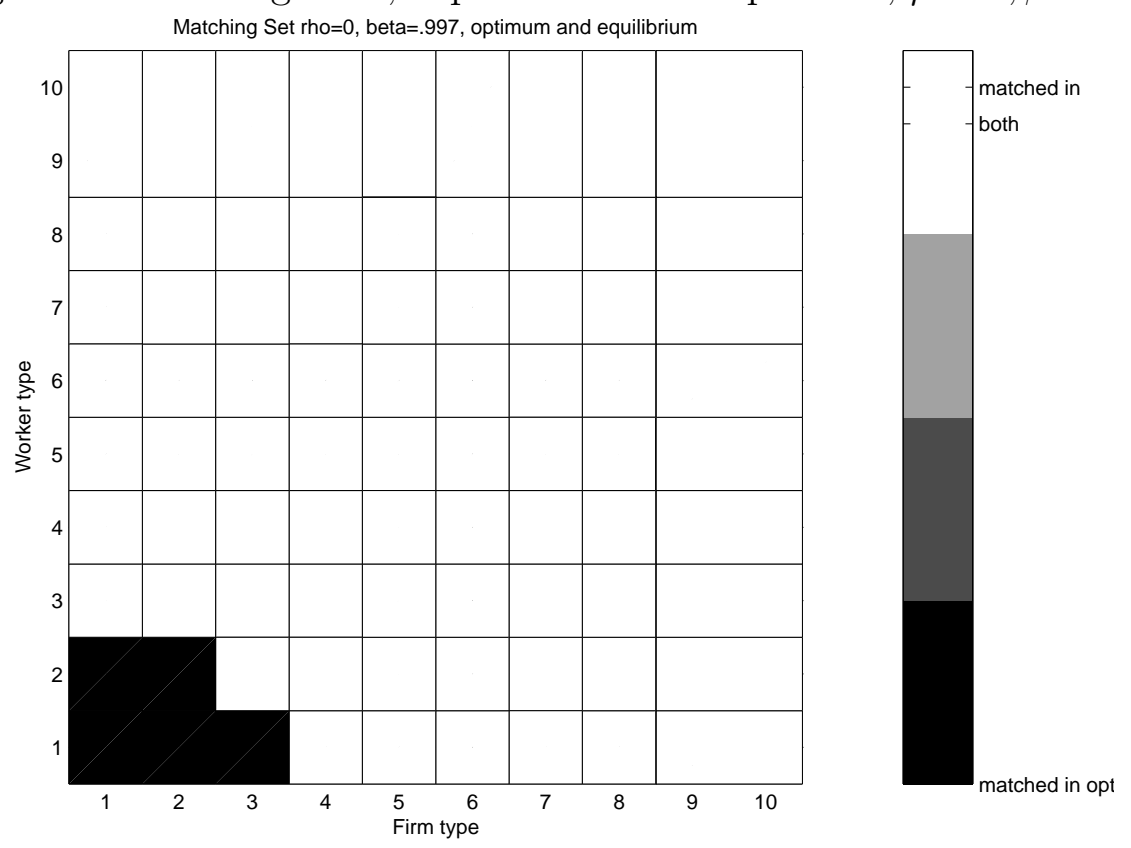


Figure 6: Matching Rule, Equilibrium and Optimum, $\rho=1, \beta=.997$

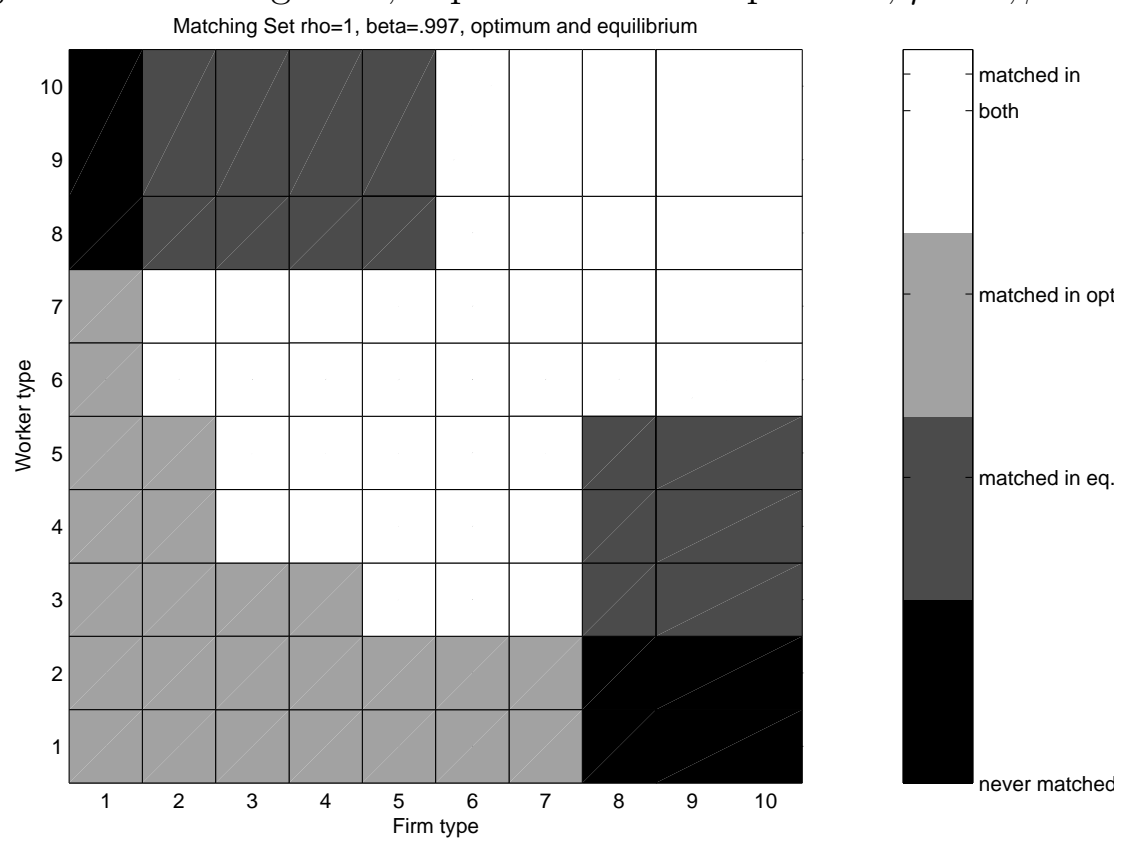

The optimal matching rule is very different from the equilibrium matching rule. It does not, however, imply necessarily less unemployment. The main difference is in the composition of unemployment. The discount factor influences the optimal matching rule. In the limit, when $\beta \rightarrow 1$, one expects the optimal rule to coincide with the Golden Matching Rule, depicted in Figure 7. In the model, this happens when $\beta>99$. As the discount factor gets lower, the zone in which matches are not accepted decreases steadily. This is no surprise: a lower discount factor is tantamount to a higher weight on the present. Hence, today's output is favored. Under the parametrization of the model, the optimum economy has a lower unemployment rate for all discount factors, with the unemployment rate increasing with $\beta$. Notice, finally, that the simple unemployment scheme introduced above pushes the equilibrium away from the optimum.

\subsection{Decentralizing the Optimum}

With the optimum characterized, a natural next step is to look for ways to decentralize it. In this section, some preliminary reflections on this topic are given. 
Figure 7: Golden Matching Rule

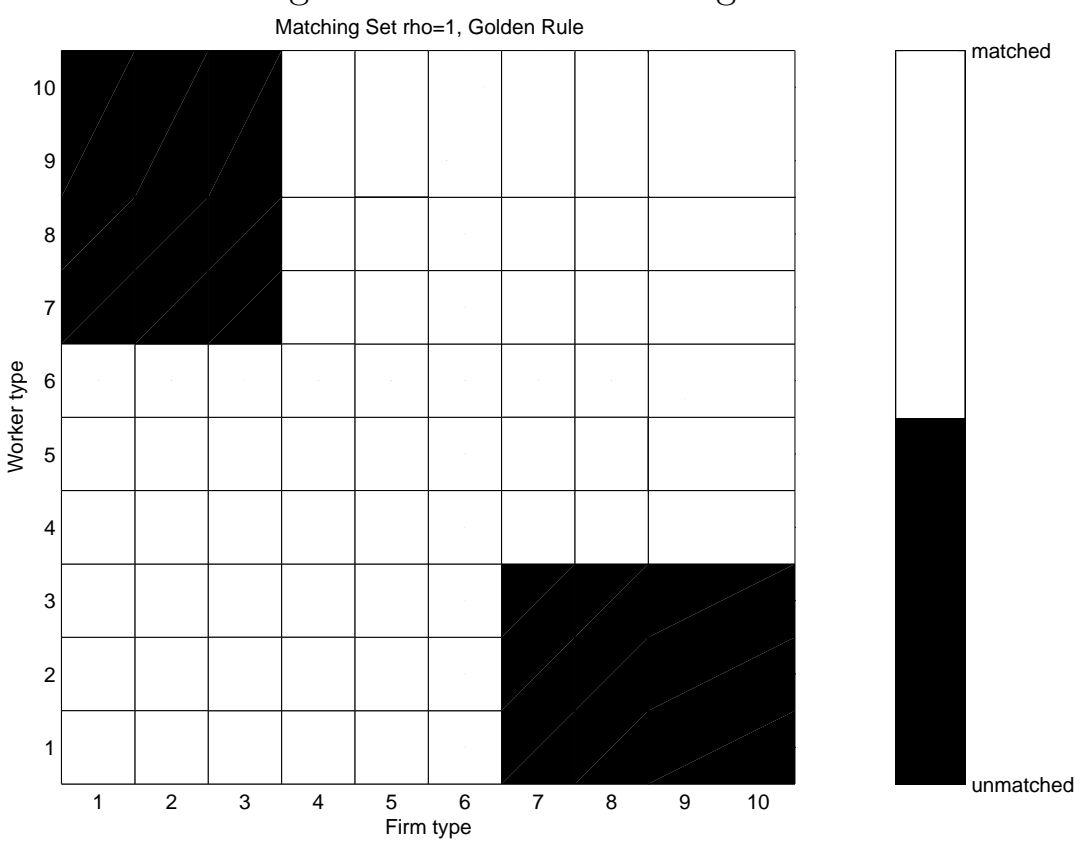

\subsubsection{Type-dependent Decentralization}

Assume the government observes types. What can be done to induce workers and firms to match according to the optimal decision matrix I? A first idea is to give a subsidy to pairs that need to be induced in matching, and tax heavily pairs that need to be discouraged. A tax on all productive matches can then be used to ensure budget balance. Ideally, the government would be able to give the same subsidy to all pairs that need to be induced to match. This is not easy to implement, however, as these taxes and subsidies change continuation values for all. A second idea is to individualize taxes and subsidies.

Following the literature on mechanism design, yet another idea is to introduce a payment that is linked to the externality imposed by the pair. Doing this requires having an expression of the effect of a match (or a non-match) on the distribution. Take a look at the expression for $\Phi,(12)$. The numerator counts the number of $i k$ pairs that refused to match in the previous period and then evolved. Assume the planner/government wants to induce pairs $j l$ to take the opposite decision. Then the number of affected pairs has to be added to the numerator if the pairs original decision 
is to match, and subtracted to the numerator if the original decision is not to match. A new numerator can be defined as

$$
\begin{aligned}
A_{l}=\sum_{i} \sum_{k}\left[\left(M_{i k}+\Phi_{i} \Omega_{k} N\right)\left(1-I_{i k}\right) X(j \mid i)\right] & \\
& -\left(M_{j l}+\Phi_{j} \Omega_{h} N\right)\left(1-I_{j l}\right) X\left(x_{l} \mid x_{j}\right) \\
& +\left(M_{j l}+\Phi_{j} \Omega_{h} N\right) I_{j l} X\left(x_{l} \mid x_{j}\right) .
\end{aligned}
$$

To obtain $\Phi$ from the numerator, one simply divides the numerator by the sum of numerators over type. Doing the same here produces an alternate distribution of un-

matched firms, $\widehat{\Phi}(l)=\frac{A_{l}}{\sum_{l} A_{l}}$. Using the same numerator and denominator expressions, but with the transitions given by $Z$ instead of $X$ yields an alternate distribution of unmatched workers, $\widehat{\Omega}$. Using this set of meeting probabilities instead of the original one and summing over all types provides an approximation of the value of the economy when the pair $j l$ changes its decision. If the planner can compute these externalities, and introduce them in the objective function of the agents, it is possible that the optimal solution can be decentralized. This remains to be seen in practice, however.

\subsubsection{Type-independent Decentralization}

If the government cannot observe types, then an expected version of the last idea of the previous subsection might work. This is especially true since the planner wants low types to match together even when not productive enough because there is no exit in this world. It would be better if the low types could just be made to stay at home. Introducing a participation fee that is equal to the expected externality of the potential entrants could limit the number of low types in the economy.

A simpler idea is to have a non-linear tax on wage and on profit. This is easy to implement. It is possible to use Genetic Algorithms in order to pick taxes and subsidies to come as close as possible to the optimal decision rule. This is performed for the benchmark parametrization with complementarities in the production function. Using a non-linear tax on both wages and firms' net profits, it is possible to come close to full employment (only the lowest possible pair doesn't match). To force high types 
to refuse low types is not achieved, however. Note that this can be seen, loosely, as guide to policy. In a world where labor markets function like the one in this paper, a non-linear tax does a better job at letting markets function optimally.

\section{The Effects of Unemployment Insurance}

In this section, the effects on Unemployment insurance are examined. Unemployment insurance has two contradicting effects in this economy. First, it decreases the employment rate of low skilled workers, thus increasing unemployment. Second, it increases the degree of sorting. The purpose of this section is to illustrate the potential of the model by contrasting the economy with and without a simple unemployment scheme, and examining the effect of increasing the risk aversion parameter of the workers. The focus is put on the Cobb-Douglas economy.

A simple unemployment insurance is assumed. The government hands out benefits $b=.15$ to all unemployed workers, and taxes the wage to keep a balanced budget. The introduction of unemployment benefits increases unemployment from $16.8 \%$ to 28.5\%. This in turn decreases mismatch, from 0.08 to 0.06 . Unemployment insurance allows some mismatched pairs to refuse to contract, which has a positive effect on the economy. But unemployment insurance allows some low productivity pairs not to match, which has a negative effect on the economy.

When skills are complementary, as in the benchmark parametrization, it is in theory possible that sorting improves sufficiently to overcome the loss due to increased unemployment. This is the case in the benchmark model. Output rises to 1.793 (from 1.788). The benchmark economy is one where a little unemployment insurance decreases mismatch sufficiently to improve output. The level of output when assuming perfect sorting at the current unemployment level, $y^{\text {sort }}$ is between 2.66 and 2.52. The loss due to unemployment ranges from $4.3 \%$ to $9.4 \%$. The loss due to mismatch can take a value anywhere between $26.3 \%$ and $31.3 \% .^{12}$ In the economy without unem-

\footnotetext{
${ }^{12}$ In percent of the first-best level of output.
} 
ployment insurance, the sorted level of output ranges from 2.73 to 2.64. Comparing these numbers to the sorted output with unemployment insurance, one can estimate that there is a loss of $\frac{2.73-2.66}{2.79} \cdot 100=2.5 \%$ due to the extra unemployment. ${ }^{13}$ But the total gain in output is $\frac{1.793-1.788}{2.79} \cdot 100=0.2 \%$. From this result, it is possible to infer that the extra sorting taking place under unemployment insurance increases output by at least $2.7 \%$ compared to the situation without unemployment insurance.

Looking at the matching set in Figure 8, and contrasting it with Figure 6, one notices that more pairs do not match, both in the region in which the planners wants them to match and the sufficiently costly, the positive effect of the extra sorting compensates the negative effect of unemployment.

Figure 8: Matching Rule, Equilibrium with UI and Optimum, $\rho=1, \beta=.997$

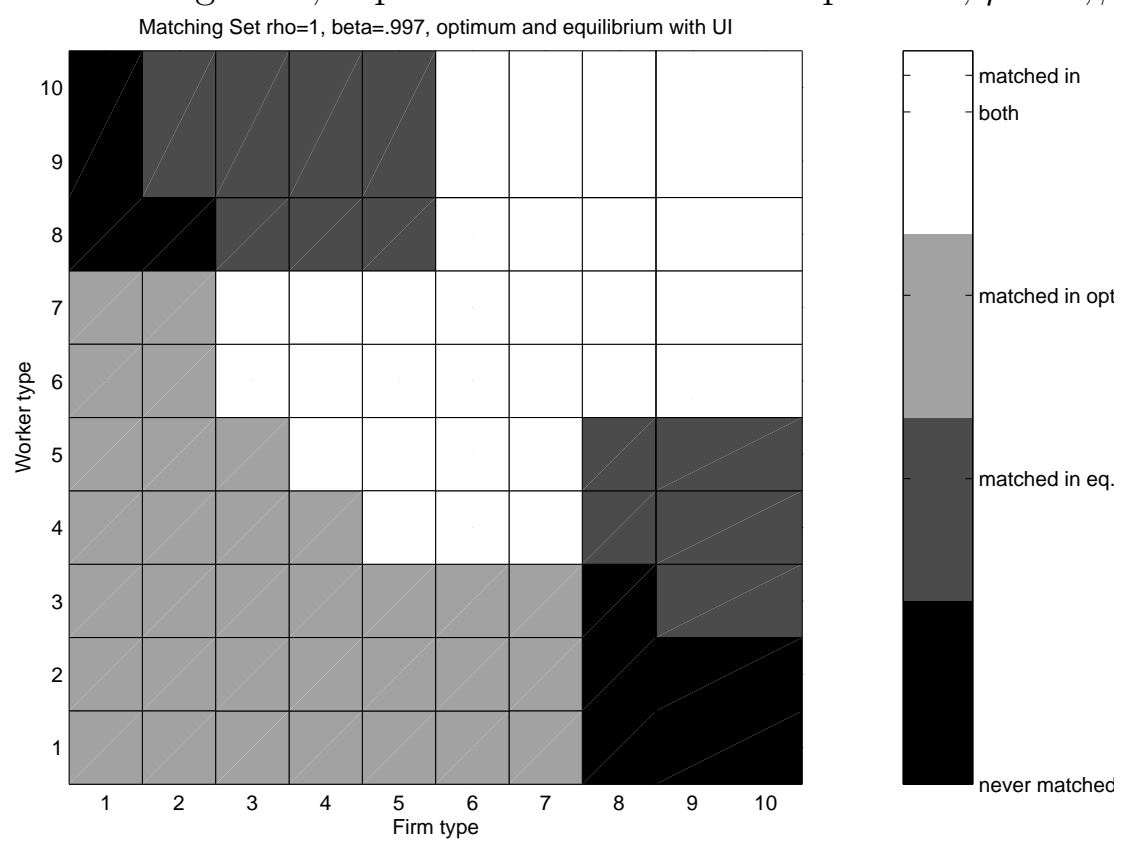

The unemployment benefits are not the only distortionary element in this economy. Taxes are distortionary, too. It is easy to isolate the effect of taxes from the effect of the unemployment insurance by solving the problem with unemployment insurance but without taxes, and thus without budget balance. At the level of unemployment insurance considered $(b=.15)$, taxes do not affect the economy. This is, in part, due

\footnotetext{
${ }^{13}$ In percentage of the first-best outcome.
} 
to the discreteness of types. Increasing unemployment insurance to .35 results in taxes having an effect on the economy. Now taxes are large enough to make a pair willing to work in the economy without budget balance switch decision.

Unemployment insurance increases the level of output (or keeps it at a similar level) in the benchmark model. But this is not necessarily an improvement. A higher proportion of unemployed workers spend more time searching. The proportion of unemployed workers in the three first unemployment duration categories in Table 3 (less than 5 weeks, 5-15 weeks, 15 -26 weeks) decreases to $29.4 \%, 26.2 \%$, and $14.6 \%$ respectively. This implies that the proportion in the last category (more than 27 weeks) increases to $29.8 \%$. The increase in unemployment duration affects mostly the lowest education level. The unemployment rate for workers with less than high school education, in the model, is now $90.2 \%$, with a median duration of 45 weeks, and 90th percentile duration of 160 weeks. Comparatively, workers with high school and some college have a $6.5 \%$ unemployment rate, and median and 90th quantile duration of 10 weeks and 30 weeks, respectively. And individuals with at least a college degree are faced with an unemployment rate of $3.4 \%$, with median and 90th quantile duration of 5 weeks and of 12.5 weeks, respectively.

\begin{tabular}{|c|c|c|c|}
\hline Unemployment Duration & US & no UI & UI \\
\hline \hline$<5$ weeks & $37 \%$ & $37.9 \%$ & $29.4 \%$ \\
\hline $5-14$ weeks & $33.4 \%$ & $29.4 \%$ & $26.2 \%$ \\
\hline $15-26$ weeks & $15.9 \%$ & $16.8 \%$ & $14.6 \%$ \\
\hline$>27$ weeks & $13.7 \%$ & $15.9 \%$ & $29.8 \%$ \\
\hline
\end{tabular}

Table 3: Unemployment duration, US and model

In addition, wage inequality is increased. The Gini coefficient for the aggregate economy is now $0.553 .{ }^{14}$ The Lorenz curves for the economy with and without un-

\footnotetext{
${ }^{14}$ Notice that the Gini coefficients takes the unemployed into account. A measure of wage inequality within wage earners like the ratio of the 90 th percentile to the 10 th percentile is reduced by the unemployment scheme, but only because low wage earners become unem-
} 
employment insurance are depicted in Figure 9. Wage levels by quantiles increase for

Figure 9: Lorenz Curves, Benchmark with and without UI

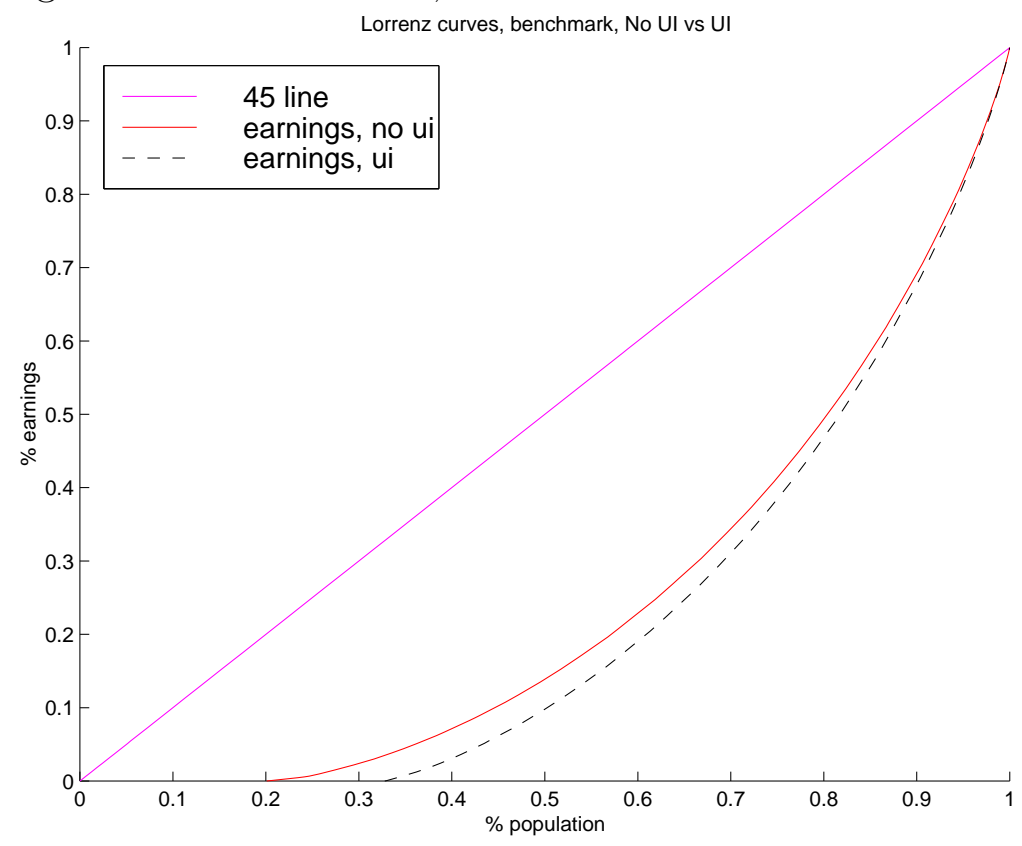

all individuals but the less educated ones, which are almost all unemployed (see Figure 10). Hence, once distributive effects of introducing unemployment insurance are taken into account, the picture is less rosy than suggested by the increase in aggregate output. Notice that, under the current parametrization, the model can account for differences between the US and European economies. Two economies can have comparable output levels, with one having a lot more unemployment, and a much longer unemployment duration. Contrary to the US/Europe case, however, the model economy with unemployment insurance has more inequality in wages.

\subsection{On the Importance of Risk Aversion}

Most matching models assume workers to be risk-neutral. Is this assumption warranted? To answer this question, the model is solved both with risk-neutral workers and with log-utility workers and with workers with $\sigma=.6$. All other parameters are at their benchmark levels. When workers are risk-neutral, there is total symmetry beployed. 
Figure 10: Wage Quantiles, US and Benchmark, UI
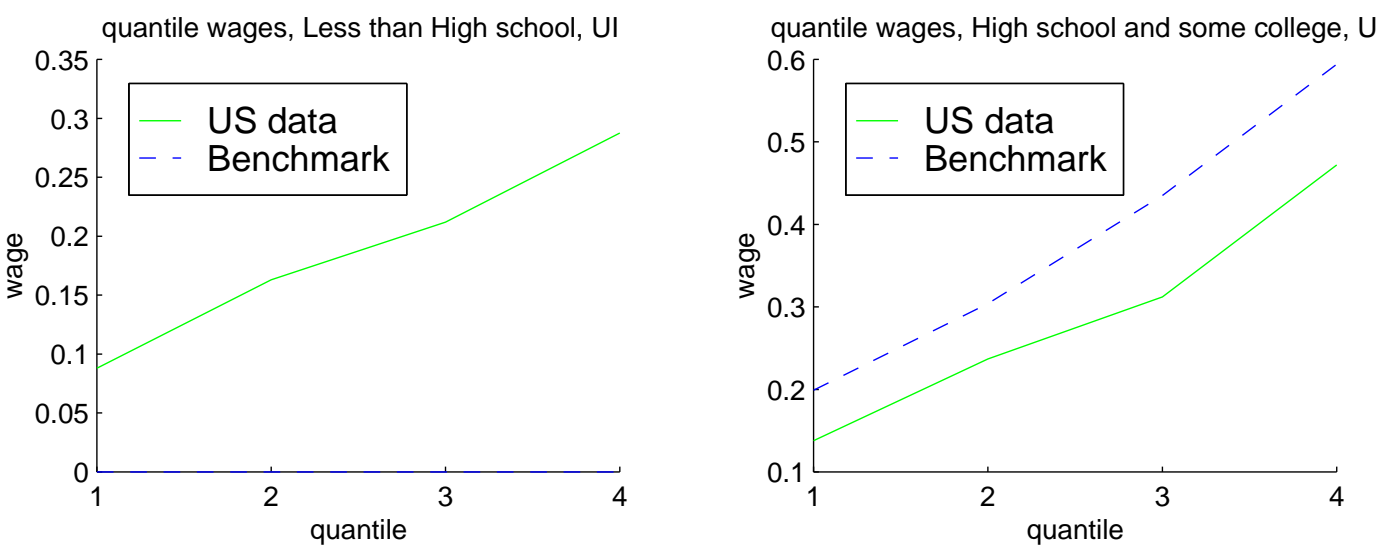

quantile wages, college graduate, UI
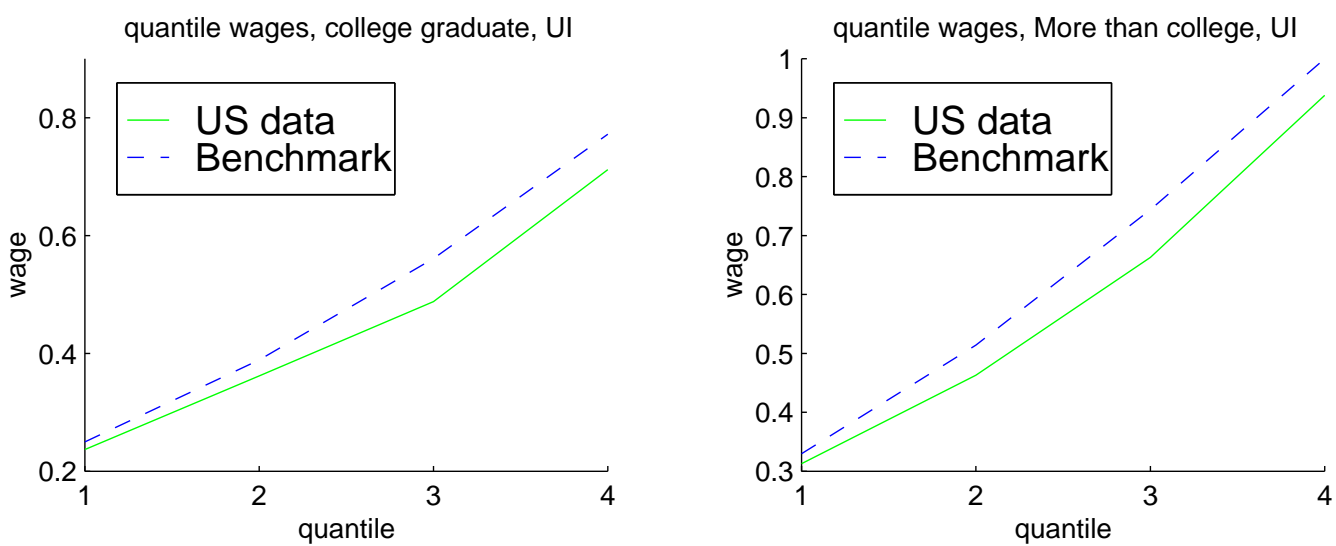
tween the firms and the workers (at the benchmark parameters). Hence, the matching set is symmetric (see Figure 11). When $\sigma=.6$, the matching set is not symmetric, and is depicted in Figure 12.

Figure 11: Matching Set, Risk-Neutral Economy
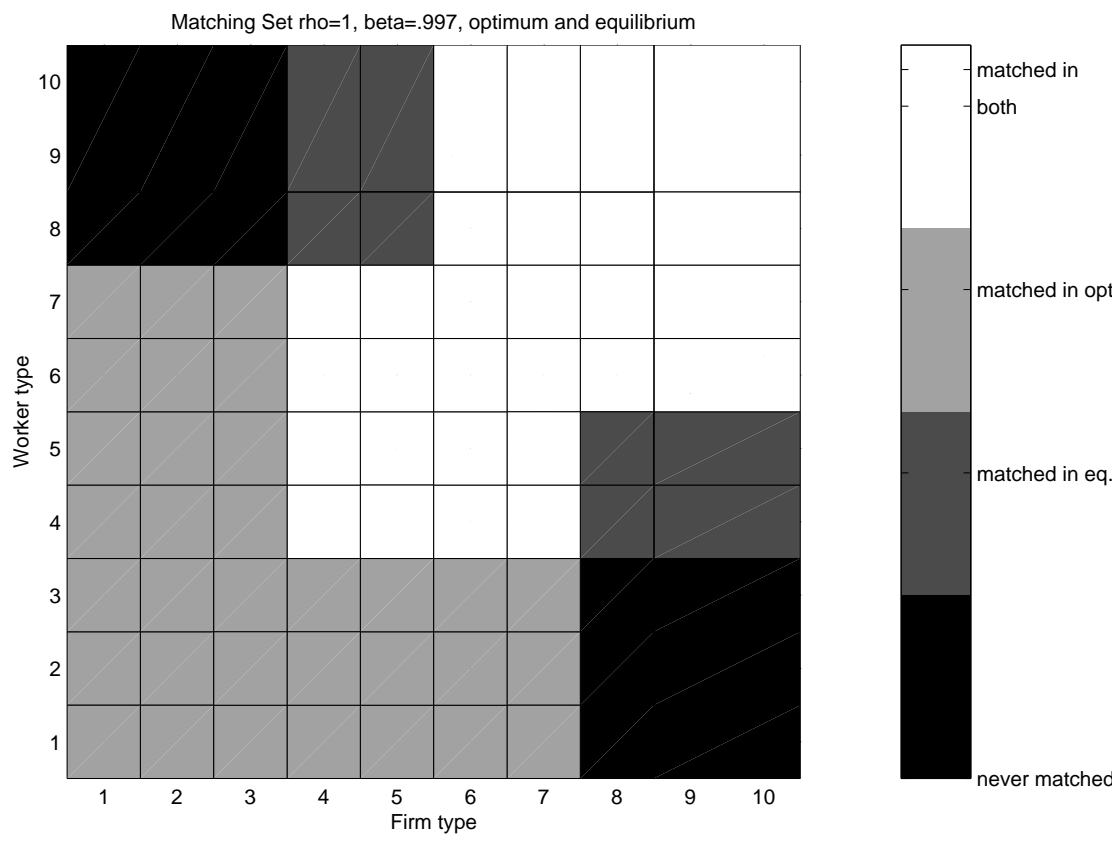

At the aggregate level, risk neutrality massively changes the unemployment rate (from $16.7 \%$ in the risk-averse economy to $29.8 \%$ in the risk-neutral one), and the Gini coefficients (0.58 in the risk-averse economy and 0.81 in the risk-neutral one). The Lorenz curves are very different under the two risk aversion assumptions (see Figure 13). The level of mismatch is lower in the risk-neutral economy, and it decreases by enough so that output is slightly higher. The unemployment rates by education level are much higher in the risk-neutral economy, with all of the lowest category unemployed, and $9.7 \%$ and $3 \%$ of the other categories unemployed.

The difference between these two economies, at the aggregate level, depends on the parametrization. When the idiosyncratic shocks are less persistent, the two economies look very much alike (almost identical unemployment rate and output level). At the individual level, however, differences are still great (although less so than in the benchmark parametrization). The introduction of unemployment insurance does not affect 
Figure 12: Matching Set, $\sigma=.6$

Matching Set rho=1, beta=.997, optimum and equilibrium

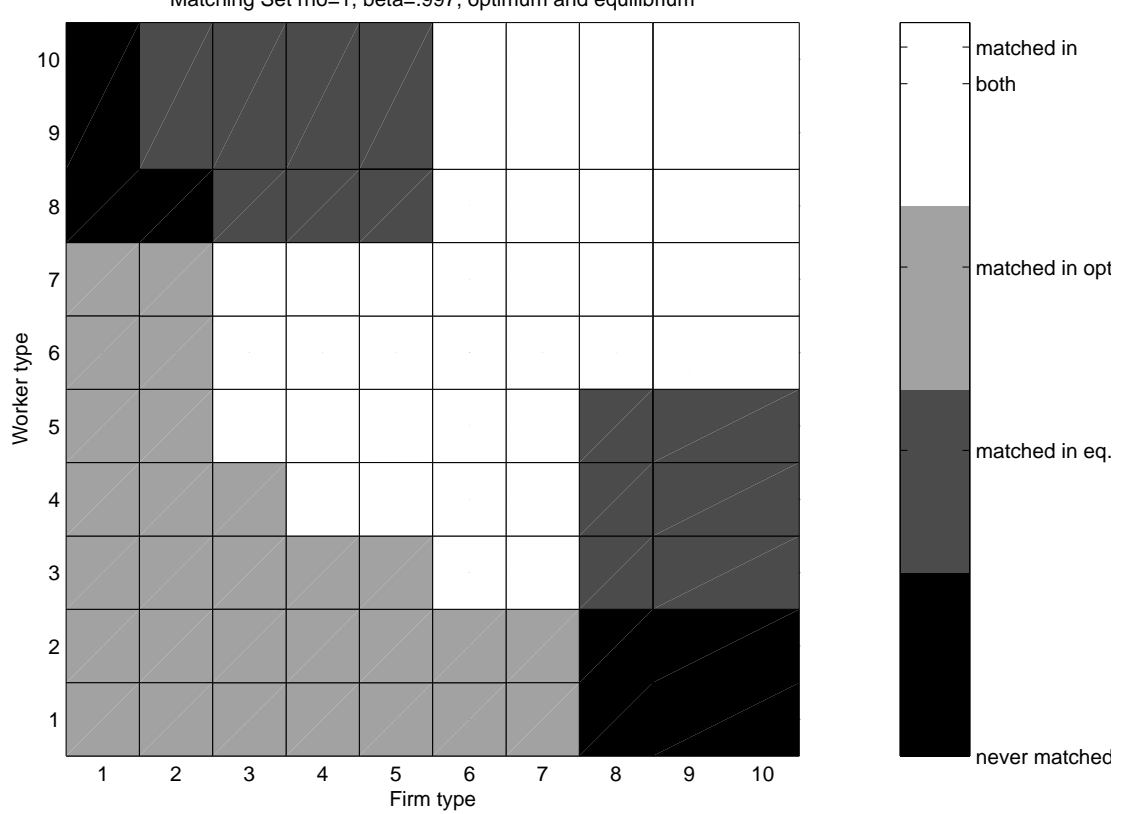

Figure 13: Lorenz Curves

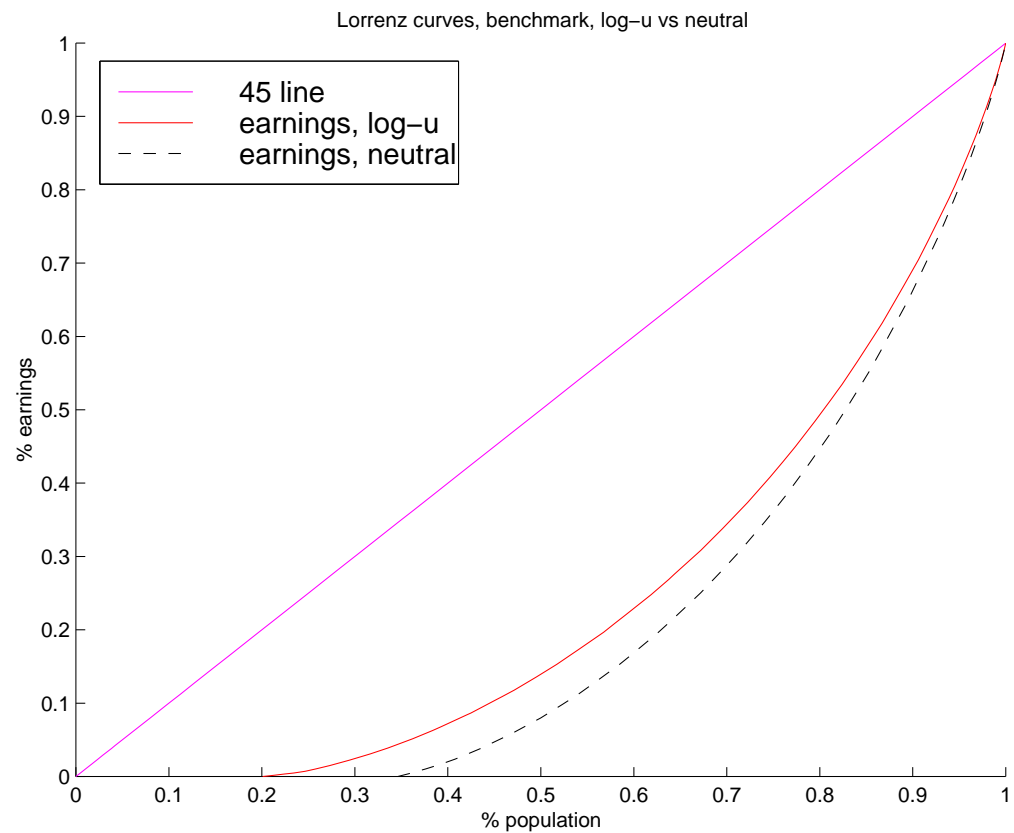


the risk-neutral economy much. Unemployment increases only a little, and the composition of unemployment remains similar. Unemployment insurance has a much greater effect in the economy with risk-averse workers. As the coefficient of risk-aversion decreases, the optimal unemployment insurance level decreases. This is a consequence of the lower level of mismatch in the economy with less risk-aversion. The risk-neutral assumption that is standard in the literature is, therefore, not innocuous.

\section{Sensitivity Analysis}

Effects of changes in parameters are discussed. This analysis serves two purposes. First, it allows to identify the parameters on which the results in the benchmark scenario depend. Second, it makes room to ask, and try to answer, a number of questions. For instance, most of the search and matching literature assumes a risk-neutral world. How do the results in such a risk-neutral world contrast with those discussed above? Under what parametrization does this assumption matters (if any)? Is it possible to create more 'white collar' (i.e. high-skill) unemployment while decreasing the level of 'blue collar' unemployment, thus replicating what happened in the last two recessions in the US? In Section 3, the effect of the change from a Cobb-Douglas to an additive production function on the results has already been examined from a matching-set perspective.

\subsection{Change in the Idiosyncratic Shock}

Assume first that the idiosyncratic shocks are less persistent. This implies that the proportion of workers that are in the extreme categories of education achievement (less than high school and more than college) is smaller. In addition, the relative efficiency of high types is higher. Home production $h$ is increased to .22 , in order to keep the same production set (see Figure 2). The unemployment rate in the economy is now much lower, at $6.2 \%$. This decrease holds across all education categories. Workers with less than a high school diploma face a $15.3 \%$ unemployment rate. Other categories have an 
unemployment rate between a $1 \%$ and $2 \%$. The probability of exiting unemployment fast is much higher now, with $67 \%$ of workers exiting after less than 5 weeks, and an additional $25.7 \%$ taking between 5 and 14 weeks to find a job. Unemployment duration is lower at all education level, with the median duration ranging from 5 weeks (no high school diploma) to 2.5 weeks (all other categories). The 90th percentile duration for the lowest education category is 15 weeks. The ratio of quantile wages over the 95th percentile wage is higher at all quantiles and for all education levels. The Gini coefficient is lower, at 0.3521 .

The second possible change that can be made to the idiosyncratic shocks is to vary the deviation parameter. This does not affect the distribution of education achievements. Once more, home production is used to keep the production set fixed. The result of a decrease in the volatility of the shock is to decrease the level of unemployment at all levels. The aggregate unemployment rate is $12 \%$. Another effect is to increase the wage level for all education levels. Some of the lowest educated workers remain unemployed for a long time: the 90th percentile duration for workers in the lowest category is 57.5 weeks. But the median unemployment duration is just 15 weeks. Other education groups remain unemployed for 12.5 or 5 weeks at most (90th percentile, high school and college or more, respectively). It follows that the Gini coefficient is smaller in this economy, at 0.3658 .

\subsection{Changing the Production Technology}

\subsubsection{Increasing Complementarity}

In the benchmark model, there is too much unemployment in the low-skill levels and not enough in the higher skill ones, relative to the US data. The low-skill workers and low-quality firms are too selective, and the high-skill and high-quality ones are not selective enough. Increasing complementarity makes high-types more patient, implying that there is more unemployment within high-skill groups. Low-type agents will not, however, match together more, resulting in an increase in their unemployment rate. As an example, the complementarity parameter $\rho$ is changed from 1 to 2 . 
The result is an increase in unemployment due to an increase in unemployment rates for all education levels. Consequently, unemployment duration is increased both at the aggregate and at the within-skill level. When unemployment insurance is introduced, the level of mismatch does not decrease by enough to keep output at a similar level contrary to what happens in the benchmark model. The model shows that the recent increase in white-collar unemployment in the US can be explained, in part, by an increase in the complementarity of the production technology. Finding a production technology that keeps blue-collar unemployment from increasing too much when the technology is introduced in the model would be better at explaining the recent recessions, however.

\subsubsection{Hierarchical Skills}

Up to now, it has been assumed that all jobs can be performed by any type of worker. In some sense, skills have been defined in terms of efficiency units. There are other ways to define skills. Starting with Vroman (1987), a large branch of the matching and heterogeneity literature has assumed that, while high-skilled workers can perform any job, low-skilled ones are only able to produce at lower types of jobs.

In this section, the production function is adapted to encompass this hierarchical definition of skills. A worker is assumed to be able to produce with firms of all types below or equivalent to his. The output produced when a worker is with a higher firm is assumed to be nil. Formally,

$$
F_{i k}= \begin{cases}0 & \text { if } i>k \\ \frac{\left(\alpha x_{i}^{\frac{1}{1-\rho}}+(1-\alpha) z_{k}^{\frac{1}{1-\rho}}\right)^{(1-\rho)}}{(1-\rho)} & \text { otherwise. }\end{cases}
$$

The experiment is made to contrast the results above with those in the rest of the literature. In papers with hierarchical skills, two types are usually assumed. Two sorts of equilibria can usually be found. ${ }^{15}$ One with perfect sorting, and one in which high types work wherever, and all unmatched individuals are low types. With a higher number of types, it is not so clear that there is perfect sorting.

\footnotetext{
${ }^{15}$ See Albrecht and Vroman (2002) for instance.
} 
In the model presented here, with two types, the only equilibrium is perfect sorting. However, once the number of types is increased to its usual number of 10, the sorting is imperfect, as can be seen in Figure 14. In this figure, the fact that lower types do

Figure 14: Matching Set, Optimum and Equilibrium, Hierarchical Skills

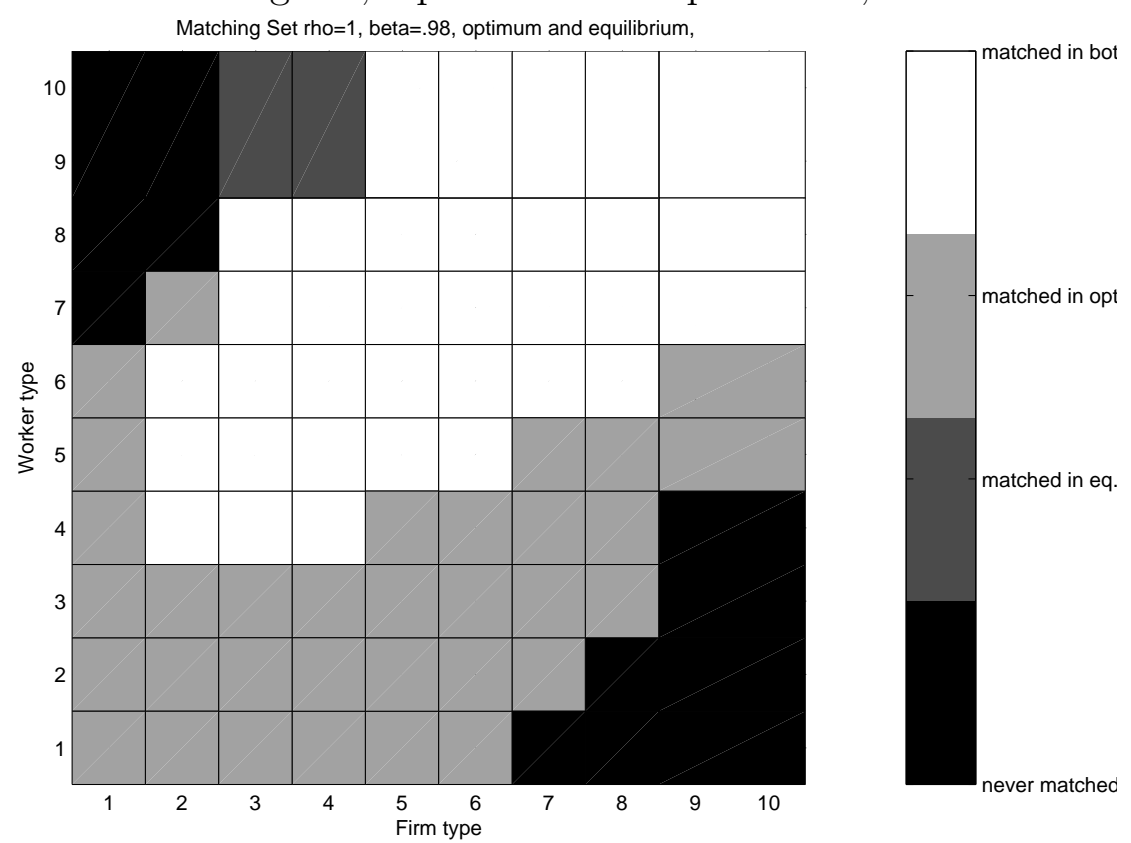

not match together is due to home production. Lowering home production eliminates that result. Another interesting feature is that the planner wants low types to match with slightly better, but also low-type, firms. This is because there is no exit from the employment market and the presence of those low workers and firms in the searching pool would disturb the pool's distribution. For now, assume that these zero production matches amount to exiting the market altogether.

In terms of the distribution of unemployment and wages, the change to hierarchical skills has the following effects. Unemployment increases slightly, and this increase is concentrated in the middle category (high school and some college), with unemployment in other categories only increasing slightly. Unemployment duration is reduced for all skill levels, the 90th percentile for workers with less than a high school diploma being less than 25 weeks. To the extent that the increase in white-collar turnover is concentrated in the lower category of white collar workers, a change to a produc- 
tion function such as the one above (hierarchical skills) can explain the increase in white-collar unemployment.

\section{Conclusion}

In this paper, a quantitative matching model applied to the labor market with heterogeneous agents on both sides of the market is solved. Search is undirected, and all types of workers are able to produce with any firm. The number of types is not restricted to two, and workers are not assumed to be risk-neutral. A numerical method is put forward to solve for the stationary optimal solution. Thus the stationary equilibrium can be contrasted with the optimum. It is shown that the equilibrium is suboptimal. It involves too much matching between extremes of the skill distribution, and not enough between low-types. Hence, the composition of unemployment is important in determining how well an economy is performing. Unemployment insurance has complex effects on the economy, but it does not typically improve upon the initial equilibrium in terms of who matches with whom. It increases the unemployment rate of lower skilled workers, but does nothing to induce ill-matched pairs to keep searching.

Introducing a simple unemployment insurance scheme encourages all types to be pickier. This has two effects. One is to increase the level of unemployment, which has negative impact on output. Low types are now even less likely to match together, a move away from the optimal solution. The second effect is to make high types more picky, thus decreasing the degree of mismatch and bringing the economy closer to the optimal solution. When this second effect dominates, unemployment insurance has a positive effect on output, which can help explain differences between the labor market performance of various countries.

In this model economy, wage dispersion both within and between skills is naturally present. Unemployment duration is linked to skills. The model can thus reproduces features of the composition of unemployment and of unemployment duration, and exhibits similar within- and between-skills wage heterogeneity as the in the data. The quantitative effects of a simple unemployment scheme are complex. Aggregate unem- 
ployment and the average duration of unemployment increase. This increase is not equally distributed, however. Low-skill unemployment and low-skill unemployment duration increase, but high-skilled individual have almost unchanged unemployment duration.

It is shown that assuming risk-neutral workers in such an environment, a standard practice in the matching literature, has important consequences for aggregate variables, but more so for the way unemployment and wages are distributed. Interesting avenues to take in order to increase the fit of the model to the data, and to maker the model more realistic range from changing the production function to capture the idea that low-type firms have a technology that is less complementary in skills than high-type firms to introducing savings and investment and allowing for entry in and exit from the labor force. In addition, the model is well-suited to discuss the distribution effects (in terms of wages, unemployment levels, unemployment duration) of different policies. Introducing policies that mimic more closely real world labor policies would be very instructive.

\section{References}

Aiyagari, S. R., J. Greenwood, and N. Guner (2000): "On the State of the Union," Journal of Political Economy, 108(2), 213-243.

Albrecht, J., and S. VRoman (2002): "A Matching Model with Endogeneous Skill Requirements," International Economic Review, 43(1), 283-305.

Davis, S. J. (2001): "The Quality Structure of Jobs and the Structure of Wages in Search Equilibrium," University of Chicago.

GoldBerg, D. E. (1989): Genetic Algorithms in Search, Optimization and Machine Learning. Addison-Wesley.

Greenwood, J., N. Guner, And J. A. Knowles (2003): "More on Mariage, 
Fertility and the Distribution of Income," International Economic Review, 44(3), $827-862$.

Hosios, A. J. (1990): "On the Efficiency of Matching and Related Models of Search and Unemployment," Review of Economic Studies, 57(2), 279-298.

SHI, S. (2001): "Frictional Assignment. I. Efficiency," Journal of Economic Theory, 98, 232-260.

Shimer, R., And L. Smith (2000): "Nonstationary Search," Princeton University.

- (2001): "Matching, Search and Heterogeneity," Advances in Macroeconomics, 1(1), Article 5.

Tauchen, G. (1986): "Finite State Markov Chain Approximations to Univariate and Vector Autoregrations," Economic Letters, 20, 177-181.

Vroman, S. (1987): "Behavior of the Firm in a Market for Heterogeneous Labor," Journal of Economic Dynamics and Control, 11, 313-329. 